\title{
The postcranial skeleton of Boreogomphodon (Cynodontia: Traversodontidae) from the Upper Triassic of North Carolina, USA and the comparison with other traversodontids
}

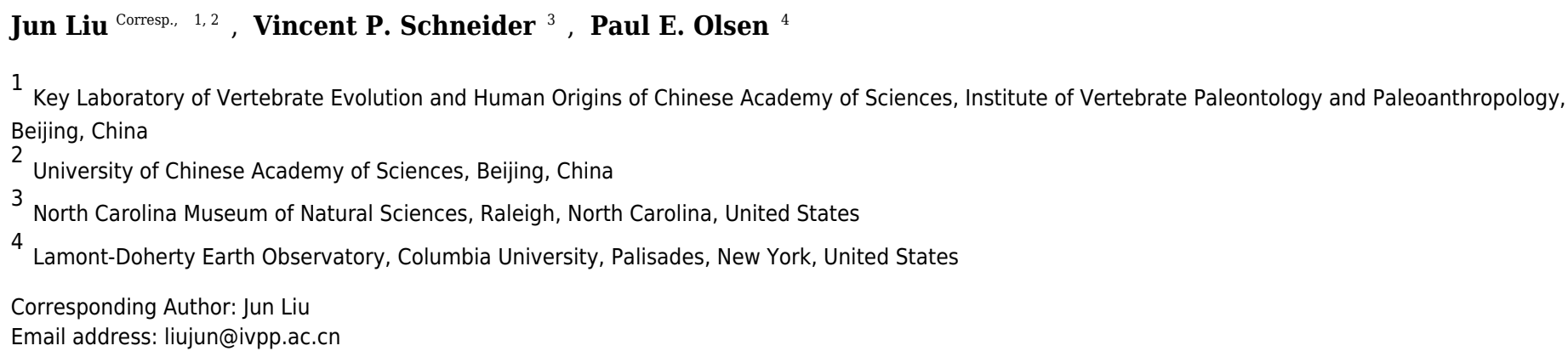

Postcranial remains of Boreogomphodon from the Upper Triassic of North Carolina are described and compared to those of other known traversodontid cynodonts. The postcranial skeleton of Boreogomphodon is characterized by four sacral ribs, simple ribs lacking costal plates, the extension of the scapular neck below the acromion process, a short scapular facet on the procoracoid, a concave anterior margin of the procoracoid, humerus entepicondyle with smooth corner, and the presence of a fifth distal carpal. Four types of ribs are identified among traversodontids: 'normal' form, tubercular rib, costal plate, and Y-shaped rib. Fossorial behavior is suggested for traversodontids with elaborate costal plates. Within Traversodontidae, the procoracoid is relatively small; the anterior process of the iliac blade extends anteroventrally to different degrees in different taxa, which facilitates retraction of the femur; and the limb bones show allometric growth in terms of length and width. 
The postcranial skeleton of Boreogomphodon (Cynodontia: Traversodontidae) from the Upper

2

3

$4{ }^{1}$ Key Laboratory of Vertebrate Evolution and Human Origins of Chinese Academy of Sciences, Institute of Vertebrate Paleontology and Paleoanthropology, Chinese Academy of Sciences,

$6 \quad$ Beijing 100044, China

$7 \quad{ }^{2}$ University of Chinese Academy of Sciences, Beijing 100039, China

$8 \quad{ }^{3}$ North Carolina Museum of Natural Sciences, Raleigh, NC, USA

9 4Lamont-Doherty Earth Observatory, Columbia University, Palisades, NY 10964, USA

11 ABSTRACT

12 Postcranial remains of Boreogomphodon from the Upper Triassic of North Carolina are

13 described and compared to those of other known traversodontid cynodonts. The postcranial

14 skeleton of Boreogomphodon is characterized by four sacral ribs, simple ribs lacking costal plates, the extension of the scapular neck below the acromion process, a short scapular facet on the procoracoid, a concave anterior margin of the procoracoid, humerus entepicondyle with smooth corner, and the presence of a fifth distal carpal. Four types of ribs are identified among traversodontids: 'normal' form, tubercular rib, costal plate, and Y-shaped rib. Fossorial behavior is suggested for traversodontids with elaborate costal plates. Within Traversodontidae, the procoracoid is relatively small; the anterior process of the iliac blade extends anteroventrally to different degrees in different taxa, which facilitates retraction of the femur; and the limb bones 
22 show allometric growth in terms of length and width.

23

24

25

26

27

\section{INTRODUCTION}

Cynodontia is a diverse clade and represents an important therapsid radiation that is especially noteworthy for including crown-group mammals. During the Early Triassic, eucynodonts diverged into two clades, Cynognathia and Probainognathia. The former includes many taxa with buccolingually (transversely) expanded postcanine teeth whereas the latter, a clade mostly represented by sectorial-toothed members, gave rise to mammaliaforms by the Late Triassic (Hopson \& Kitching 2001; Liu \& Olsen 2010). The most successful Triassic lineage of cynodonts, in terms of their species richness and specimen abundance, is Traversodontidae (Abdala \& Ribeiro 2010; Liu \& Abdala 2014). Traversodontids are characterized by postcanine teeth whose crowns are labiolingually expanded and ellipsoid-to-rectangular in outline. The upper postcanines bear a deep occlusal basin. The lower postcanines are more quadrangular than the upper ones in outline and usually contain an anteriorly positioned transverse crest (Liu \& Abdala 2014).

Boreogomphodon jeffersoni was originally described based on a left maxilla with postcanine teeth from the Tomahawk Creek Member of the Vinita Formation (Carnian) in the Richmond Basin of the Newark Supergroup, Chesterfield County, Virginia (Sues \& Olsen 1990). The same locality subsequently produced numerous cranial elements and a small number of postcranial bones that were also referred to this species (Sues \& Hopson 2010; Sues \& Olsen 1990). Plinthogomphodon herpetairus was named based on the cranial remains of a small cynodont 
43 preserved as gut content in the partial skeleton of the archosaur Postosuchus alisonae from the

44 "Lithofacies Association II" (Upper Triassic: Norian) of the Deep River basin of the Newark

45 Supergroup in North Carolina (Sues \& Hopson 2010; Sues et al. 1999). Later, Liu and Sues

46 (2010) suggested that Plinthogomphodon might prove to be a subjective junior synonym of

47 Boreogomphodon, although there are slight differences in the structure of the lower gomphodont

48 postcanines. Additional traversodontid remains, including cranial and well-preserved postcranial

49 elements, from the Pekin Formation (upper Carnian or lower Norian) of Merry Oaks Quarry,

50 Triangle Brick Company, Chatham County, North Carolina were tentatively referred to

51 Boreogomphodon jeffersoni (Liu \& Sues 2010). However, a detailed study of the skull and

52 mandible is necessary before a more secure taxonomic identification can be made.

53 Previous therapsid research has focused on the skull, only a few postcranial characters have

54 been analyzed phylogenetically, and those characters remain uncoded for most species

55 (Huttenlocker et al. 2015; Kammerer et al. 2013; Liu \& Olsen 2010). The relative neglect of the

56 postcranial skeleton also accurately describes the history of traversodontid studies (Liu \& Abdala

57 2014), although this has recently begun to change. Postcranial descriptions are published for the

58 following traversodontid taxa: Exaeretodon argentinus (Bonaparte 1963), Pascualgnathus

59 polanskii (Bonaparte 1966), Massetognathus pascuali (Jenkins 1970b), Luangwa drysdalli

60 (Kemp 1980a), Menadon besairiei (Kammerer et al. 2008), Andescynodon mendozensis (Liu \&

61 Powell 2009), Protuberum cabralense (Reichel et al. 2009), and Massetognathus ochagaviae

62 (Pavanatto et al. 2015). Here we describe the postcranial skeleton of Boreogomphodon from the

63 Pekin Formation of North Carolina and use it to review postcranial variation across 
64 Traversodontidae.

65

66

67

68

69

70

71

72

73

74

Material NCSM 20698, skull with lower jaws, most of the postcranial skeleton; NCSM 20711, skull with lower jaws, anterior part of the postcranial skeleton including $\sim 27$ nearly continuous vertebrae; NCSM 21370, skull with lower jaws, and partial postcranial skeleton including nearly complete left forelimb.

\section{DESCRIPTION}

\section{Axial skeleton}

NCSM 20698 includes a nearly complete vertebral column, with 27 mostly articulated vertebrae. The total number of presacral vertebrae is probably 24 , and there are four sacrals.

Cervical series. It is difficult to distinguish between cervical and dorsal vertebrae in nonmammaliaform cynodonts due to the presence of cervical ribs. Brink (1954) differentiated cervicals from dorsals based on the presence of the tallest neural spine on the first thoracic vertebra and identified five cervicals in Thrinaxodon. Jenkins (1971) distinguished between cervical and dorsal vertebrae based on the orientation of the zygapophyses and transverse processes and the morphology of the neural spine. He used these criteria to conclude that, like crown mammals, Thrinaxodon and Cynognathus contained seven cervicals (Jenkins, 1971). Neither set of criteria can be applied to the material under study here and thus the number of cervicals remains uncertain.

The cervical vertebrae are hidden in NCSM 20698 but exposed in NCSM 20711, so the following description is based on the latter specimen (Fig. 1). No proatlas or atlas can be 
85

86

87

identified. The centra of the second (axis), third and fourth cervicals are broken, with only the right sides partially preserved. The fifth centrum shows only the anterior end. However, their neural spines are well-preserved. The axis centrum is nearly seven millimeters long; two millimeters longer than that of any successive vertebra. The axial neural spine is a broad blade, approximately $10 \mathrm{~mm}$ long. Its strongly concave dorsal margin agrees with Menadon besairiei (Kammerer et al. 2008) but differs from that taxon in having a convex rather than concave posterior half. Transversely, the spine is thin through the middle portion, but its thickness increases anteriorly and posteriorly, ending in a tuberosity. Menadon and now Boreogomphodon are the only traversodontids whose axial neural spine has been described.

The neural spine of the third cervical (C3) is canted posteriorly behind the posterior process of the axial spine, with a height equal to the posterior margin of the axial neural spine. Thus, it is proportionately taller than that of Menadon besairiei (Kammerer et al. 2008). On the fourth through seventh cervicals, the neural spines are tall, narrow, and slightly canted posteriorly. The neural spines on the third through fifth cervicals abruptly taper toward the apex and are triangular in lateral view. The neural spines on the sixth and seventh vertebrae are distinctly taller than those that precede them. The transverse processes of the third and fourth cervicals are stout and directed posterolaterally and ventrally.

The second (axis) through fifth cervical ribs are preserved in NCSM 20711. In lateral view, each rib is a short curved rod that is directed posteroventrally. Each rib is approximately $7 \mathrm{~mm}$ in length; slightly longer than the corresponding centra. Vertebral articulations of the ribs are not exposed. 
106

107

108

109

110

111

112

113

114

115

116

117

118

119

120

121

122

123

124

125

126

Dorsal series. Based on the structure of the posterior ribs, the dorsal vertebral column in traversodontid cynodonts is either relatively undifferentiated (e.g., Exaeretodon sp., Bonaparte 1963 ) or divided into a "thoracic" and "lumbar" region (e.g., Pascualgnathus polanskii, Bonaparte 1966). The ribs are poorly preserved in known specimens of Boreogomphodon, therefore assessment of any division in the dorsal column is impossible.

In NCSM 20698, 14 dorsal vertebrae are exposed and form the basis for the following description (Figs. 2, 3). The centrum is amphicoelous, approximately circular in cross-section, and slightly constricted at mid-length. Its ventral surface is smooth without a keel. There are no intercentra. The anteroposterior lengths of the centra of the anterior dorsal vertebrae measure approximately $5 \mathrm{~mm}$ and slightly increase posteriorly, reaching $6 \mathrm{~mm}$ for the more posterior dorsal vertebrae except for last three, where they are $5.3 \mathrm{~mm}$.

In lateral view, the neural arch joins the centrum along an irregular suture. The pedicles are incised anteriorly and posteriorly to form vertebral notches, of which the latter are invariably more deeply incised. No anapophyses are present. The transverse processes are reduced into small bulges on the pedicles. Their positions vary along the dorsal column. Anteriorly, the processes arise from the anterior half of the pedicles, close to the prezygapophyses, whereas on the last three dorsals, they arise from the pedicles at a point adjacent to the postzygapophyses.

The articular facets of the prezygapophyses mainly face medially and slightly dorsally against the ventrally and laterally directed articular facets of the postzygapophyses. The prezygapophyses are thin blades that extend slightly beyond the level of the anterior margin of the centrum. The postzygapophyses extend posteriorly from the base of the neural spine beyond 
127 the posterior margin of the centrum. The neural spines decrease remarkably in height posteriorly.

128 They shift to the posterior ends of the neural arches, extend posteriorly beyond the posterior rim

129 of the centrum, and lie above the prezygapophyses of the succeeding vertebra. The morphology

130 of the posterior dorsal vertebrae is generally characterized by a nearly flat dorsal surface not

131 including the neural spine (Fig. 2C, D).

132 The dorsal ribs articulate with costal foveae on the anterior dorsal vertebrae in

133 Massetognathus and Menadon (Jenkins 1970b; Kammerer et al. 2008), which are intervertebral

134 in position. The situation in Boreogomphodon is not clear-cut. The ribs lack any structural

135 specialization. The length of anterior dorsal ribs is approximately $33 \mathrm{~mm}$ in NCSM 20711,

136 whereas the length of an isolated rib is approximately $20 \mathrm{~mm}$ in NCSM 21370 (both specimens

137 have similar skull length).

138 Sacral series. The lack of a preserved ilium somewhat complicates identification of the sacral

139 series. In Thrinaxodon and Cynognathus, the sacral centra are similar in length to those of the

140 lumbar region, but tend to be narrower and more constricted at the middle (Jenkins 1971).

141 Following this criterion, four sacral vertebrae are identified in NCSM 20698 (Fig. 3). The

142 transverse processes and the zygapophyses of the first sacral vertebra are more slender than those

143 of the last dorsal vertebra. The zygapophyseal facets are nearly parallel to the parasagittal plane.

144 The first left sacral rib and second right sacral rib are still articulated with the centra. The

145 first sacral rib is wider than the last dorsal rib, whereas the latter appears to be wider than the

146 second sacral rib. The second right sacral rib is approximately $6 \mathrm{~mm}$ long and has a distinctly

147 expanded distal end. One isolated element (sr3? in Fig. 3) is identified as a sacral rib with an 
148 149 150 151

expanded distal end. It is $7 \mathrm{~mm}$ long, $4 \mathrm{~mm}$ wide proximally, and $6 \mathrm{~mm}$ wide distally. Posteriorly, there is another sacral rib (sr4?), which is more slender than the anterior ones. As in the sacral ribs of other cynodonts, the capitulum and tuberculum are confluent and the sacral ribs are not fused to the corresponding vertebrae.

Caudal series. Three anterior caudal vertebrae are exposed in ventral view in NCSM 20698 (Fig.

3). Each centrum is approximately $4 \mathrm{~mm}$ long.

\section{Pectoral girdle}

Most elements of the pectoral girdle are preserved in NCSM 20711 (Fig. 4A), including the left clavicle, left scapula, interclavicle, and coracoids. The left procoracoid and coracoid are firmly connected along a serrated suture, whereas the incomplete right procoracoid is isolated. Most elements are also preserved in NCSM 20698 (Fig. 4B-E), but only the left scapula and right procoracoid are well exposed.

Scapula. The scapula is relatively small. In NCSM 20698 (Fig. 4B-D), it is $20 \mathrm{~mm}$ tall, compared to a humerus length of $29 \mathrm{~mm}$. The scapula is bowed laterally, with a an elongate blade whose lateral surface is marked by a narrow but deep fossa. This fossa extends from the dorsal part of the blade to approximately its midpoint. The fossa served as the origin for the deltoid and teres minor muscles, as reconstructed by Kemp (1980).

The posterior border of the scapula extends close to the edge of the glenoid as a clearly defined crest, although at the base it is merely a low ridge and not a free flange as along the anterior border. The anterior flange extends only for about two thirds of the dorsal portion of the scapular blade, ending above the scapular neck. The dorsal portion of this flange is a thin sheet 
169

170

171

172

173

174

175

176

177

178

179

180

181

182

183

184

185

186

187

188

189

of free-standing bone. The acromion process extends in a position similar to that of Luangwa or

Menadon but is less developed (Kammerer et al. 2008; Kemp 1980a). The scapula is constricted

and elongate between the acromion process and the glenoid portion, and the neck is more

pronounced than in Massetognathus (Jenkins, 1970b) and Exaeretodon (Bonaparte 1963; Jenkins 1970b).

The base of the scapula bears a slightly convex semicircular glenoid facet. The articular surface is rough, indicating an extensive cartilaginous covering in life. It faces posterolaterally as well as ventrally.

Procoracoid. The procoracoid is identified by the presence of a procoracoid foramen. A bone in NCSM 20698 is identified as a right procoracoid in lateral view (Fig. 4E). It differs from the procoracoid of other known traversodontids in its possession of an acute anterior tuberosity.

The bone is an ax-shaped plate (Fig. 4A, E). The procoracoid foramen is close to the concave anterodorsal border of the bone. The articular surface for the scapula forms an obtuse angle to the anterodorsal border. The dorsal edge is short, and the procoracoid does not participate in the formation of the glenoid.

Anterior to the foramen is a shallow fossa that accepted at least a portion of the supracoracoid muscle. An anteriorly directed ridge, which is more prominent in NCSM 20698, separates the supracoracoid origin from the remainder of the lateral surface of the procoracoid. Ventral to this ridge, a crescentic depression faces anteroventrally and probably represents the origin of the biceps brachii muscle. The ventral margin of this fossa forms a sharp, strongly convex keel. The procoracoid protrudes anteriorly far beyond the procoracoid-scapula contact, 
190

191

192

193

194

195

196

197

198

199

200

201

202

203

204

205

206

207

208

209

210

forming a swollen terminal tuberosity. This protrusion increases the area for the attachment of biceps and possible coracobrachialis.

Coracoid. The coracoid contacts the procoracoid in NCSM 20711 (Fig. 4A). It is larger than the procoracoid. Although not preserved in articulation with the scapula, its robust anterodorsal margin would have contacted the supraglenoid buttress above and formed the coracoid portion of the glenoid. The posterodorsal margin of the coracoid is concave. The posterior end forms a slightly elongated process, which is incomplete but probably terminated in a tubercle for the origin of the coracoid head of the triceps. The ventral side of the lateral surface of the coracoid is indented to form a shallow fossa for the origin of the coracobrachialis muscle. The fossa extends onto the posteroventral corner of the lateral surface of the procoracoid.

Clavicle. The lateral half of the clavicle is a slender rod that is directed dorsolaterally. The medial half consists of a gradually expanding, spatulate plate, which is directed medially and horizontally (Fig. 4A). The long axes of the medial and lateral portions intersect at an angle of about $150^{\circ}$. The medial plate is bordered by rather sharply defined edges. The posterior edge becomes distinct from the clavicular shaft at approximately the midpoint of the clavicular shaft where the shaft has its greatest curvature. The anterior edge is set off from the clavicular shaft more abruptly, giving the medial plate a slightly asymmetrical appearance. The medial plate of the left clavicle is articulated with the anteroventral concavity of the interclavicle. The clavicular facet for the acromion on the distal end is not well exposed but it contacts the left scapula.

Interclavicle. The interclavicle is similar to that of Thrinaxodon (Jenkins 1971). It is cruciform with a long posterior ramus and a short transverse bar (Fig. 4A). The anterior triangular part is 
211 slightly convex, and the anterior and lateral ridges are not so distinct. The concavities defined by

212 the anterior and lateral ridges are shallow, and the left one is in contact with the medial end of

213 the clavicle. The posterior rectangular portion of the interclavicle is nearly flat except for a low

214 but distinct posterior ridge in the center. The posterior margin is slightly expanded transversely.

215 Forelimb

216

The forelimb is preserved in NSCM 20698, 20711 and 21370, including two articulated

217 hands. An articulated manus is rare among traversodontids being known previously only in

218 Exaeretodon (Bonaparte 1963). The bones of NCSM 21370 are better ossified than those in the

219 other two specimens. NCSM 21370 includes a nearly complete left hand, in which a set of nine

220 carpals and most of the phalanges are preserved. The following description is mainly based on

221 this specimen.

222 Humerus. The humerus is highly similar to that in most traversodontid cynodonts except

223 Exaeretodon (Bonaparte 1963) (Fig. 5). The width of its proximal end, measured from the lesser

224 tuberosity to the region of the greater tuberosity, equals approximately one third the total length

225 of the humerus. The maximum width across the epicondyles is about $45 \%$ of humerus length

226 (Table 1); this ratio is exceeds 50\% in Exaeretodon (Bonaparte 1963).

227 The proximal half of the humerus is composed of two planes, the deltopectoral crest and the

228 shaft, which intersect along the broad bicipital groove at an angle of around $105^{\circ}$. The short

middle shaft connecting the expanded proximal and distal ends is triangular in cross-section. The

expanded distal half of the humerus is triangular in dorsal view. The proximal and distal articular

ends of the humerus are as well-ossified as in large-sized cynodonts, differing from those of the 
232 similar-sized Thrinaxodon (Jenkins 1970b, 1971; Kemp 1980). The rounded humeral head is at

233 the center of the strap-shaped surface of the proximal end. Its boundary is not obvious because

234 the articular surface is confluent with the lesser tuberosity medially and with the proximal

235 margin of the deltopectoral flange laterally. The greater tuberosity is hard to discern. The lesser

236 tuberosity is set apart from the head by a slight depression across the strap-shaped proximal

237 articular surface. The broad deltopectoral flange amounts to nearly half the total length of the

238 humerus. It is thin and flat, but thickens towards the junction with the middle shaft. The free

239 margin of the flange curves distinctly ventrally. The dorsal bony ridge on the dorsal side

240 extending across the flange as in ?Cynognathus is evident, although it is not clearly preserved

241 (Jenkins 1971).

Arising from the robust ectepicondylar region, a thin supracondylar flange extends

proximally as well as somewhat dorsally in NCSM 20698. Its anterior margin is straight, not

curved. The ectepicondylar foramen does not open on the dorsal surface, but a concave fossa

appears to be present on the ventral surface of the proximal side of the flange, in particular, on

the right humerus of NCSM 20711. It indicates that the ectepicondylar foramen is closed. The

long, oval entepicondylar foramen is enclosed by a stout bar of bone, which arises from the

entepicondylar region and continues to the deltopectoral flange (Fig. 5E).

The capitulum is bulbous and contributes to the thickness of the ectepicondylar region. Its

articular surface is entirely confined to the ventral aspect of the humerus where its surface is 
253

254

255

256

257

258

259

260

261

262

263

264

265

266

267

268

269

270

271

272

273

capitulum. A shallow, narrow groove represents the trochlea. The dorosoventral principal axis of this groove is slightly oblique as in Massetognathus (Jenkins 1970b). The ulnar condyle is well developed and contacted the sigmoid notch of the ulna. The thickness of the ectepicondylar region is much greater than that of entepicondylar region. The entepicondyle is a stout process but less dorsally developed and thus continuous with the posteromedial margin, as in Exaeretodon, contrasting with the angular shaped entepicondyle of Luangwa and Pascualgnathus (Bonaparte 1963; Bonaparte 1966; Kemp 1980a).

Radius. The radii are articulated with the ulnae in all specimens (Fig. 6). The radius is a sigmoid bone with expanded proximal and distal ends. The distal half of the shaft is curved posteriorly and slightly medially to facilitate its crossing over the anterior aspect of the ulna. The proximal articular facet is oval or nearly semicircular, with a nearly straight edge along the posteromedial side. The facet forms a shallow concavity sloping medially. On the posterolateral aspect of the proximal end a protuberance bears a facet for articulation with the ulna. A flange or ridge for insertion of the biceps brachii is not evident on the radii of NCSM 20698 and this region is not exposed in NCSM 21370. The distal end of the radius is triangular in outline, expanding gradually toward the distal articular facet. Along the anterolateral side of the rim is a tuberosity for contact with the distal end of the ulna.

Ulna. The ulna is a sigmoid bone with an anteroposteriorly expanded proximal end (Fig. 6C, E). In lateral view, its shaft is narrow, with the distal end evenly expanded mediolaterally and the proximal end expanded primarily anteriorly. An olecranon process is not developed. As preserved, the semilunar notch is a relatively shallow, slightly concave facet with a rather 
274 straight posterior margin and a nearly semicircular anterior margin. This facet is inclined mainly 275 medially.

276 The ulnar flange on the medial side of the shaft for the interosseous ligament (Jenkins 1970b)

277 is not well exposed. The radial notch is represented by a fossa on the medial side of the anterior 278 surface, immediately distal to the sigmoid facet. The posterior surface of the ulna is smooth.

279 Carpus. Nine carpals have been identified, including the ulnare, intermedium, radiale, two centralia, and four distal carpalia; at least one distal carpal is missing. The ulnare is a stout bone, longer than wide in anterior and posterior view. It is constricted between its proximal and distal ends and the medial edge is longer than the lateral edge in plantar view. Its proximal end articulates not only with the distal end of the ulna but also the intermedium. The thickness of the bone is greater dorsally than ventrally so that the bone is nearly triangular in lateral view. The distal surface bears a small facet for articulation with the fourth and fifth distal carpals; the medial surface bears a deep groove for the reception of the lateral centrale (c2). The intermedium is a small rounded bone and only exposed in dorsal view (Fig. 6D, E). It underlies the ulna and lies between the radius and the ulnare. With its cartilaginous component, it would have likely contacted the lateral centrale and possible radiale distally. The radiale is stout, with an irregular quadrangular shape, and is best exposed in ventral view (Fig. 6B-E). Its proximal surface is a rounded facet for articulation with the radius. It contacts two centralia with anteromedial 292 (dorsomedial) and anterolateral (dorsolateral) facets; distally it touches the distal carpal 2 (Fig. $6 \mathrm{~B}, \mathrm{D}, \mathrm{E})$. This was likely the original relationship in life because the same pattern is observed in both NCSM 20698 and 21370. No pisiform is present. The medial centrale (c1) is rectangular, 
295

296

297

298

299

300

301

302

303

304

305

306

307

308

309

310

311 312

313

314 315

with its proximodistal length shorter than those of the other axes. The lateral centrale (c2) is a flat, nearly square bone. The medial and part of its ventral surfaces are covered by the radiale, so the lateral centrale is exposed as a small triangle in ventral view (Fig 6B). Its distal end articulates with distal carpals 3 and 4 . Although only distal carpals 2 to 4 are preserved, there were probably five in total because distal carpal 1 is present in all described traversodontid manus (Bonaparte 1963; Jenkins 1971; Kemp 1980b). All distal carpalia are somewhat nodular. The third and fourth distal carpals have the same size, and both are slightly larger than the second and much larger than the fifth carpal.

Metacarpal. Four metacarpals are preserved in NCSM 21370. All five metacarpals are preserved in NCSM 20698 but the fifth is incomplete. The metacarpals are elongate and dumbbell-shaped and vary only in shaft length, with IV $>$ III $>$ II $>$ I. In ventral view, the metacarpals appear nearly symmetrical, their proximal ends flaring somewhat less laterally than the distal ends. The proximal articular facet of each metacarpal is gently convex, whereas the distal facet is flat.

Phalanges. In NCSM 21370, the fourth and fifth digits have three phalanges, whereas in NCSM 20698, the first digit has two phalanges, the second digit has at least two phalanges, and the third digit has three phalanges (Fig. 6A, E, F). The inferred digital formula of the manus is 2-3-3-3-3. The phalanges are more slender than those of Exaeretodon and Cynognathus (Jenkins 1971) and flat in lateral view. Proximal phalanges are elongate and dumbbell-shaped with the articular ends similar in size and proportions. They are moderately constricted at midlength. The penultimate phalanges are also elongate and dumbbell-shaped. The proximal and distal ends are similar, with 
316

317

318

319

320

321

322

323

324

325

326

327

328

329

330

331

332

333

334

335

336

proximal end being slightly wider. The midlength constriction is much narrower than on the proximal phalanges. The articular surface for the ungual phalanx is concave. The fourth and fifth ungual phalanges are slender, tapering cones (Fig. 6A). The proximal articular facet is convex in ventral view. The first and third ungual phalanges are short (Fig. 6F).

\section{Pelvic Girdle}

The left ischium in NCSM 20698 is the only element of the pelvic girdle that could be studied (Figs. 3, 7). The ischium is composed of a proximal head and a ventromedially enlarged plate. Its acetabular surface is oval, concave, and occupies the anterolateral surface of the head. The articular facets for the ilium and pubis are convex. The ischium is slightly constricted below the head, forming a short neck with the plate. The ischial plate is fan-shaped, with an expanded distal part. The dorsal margin of the plate is mediolaterally expanded by a ridge extending from the middle of the lateral acetabular rim to the posterodorsal corner of the plate. The dorsal surface is smooth without an obvious groove. The portion of the plate below the ridge is thin. The posterior edge of the plate is short and straight in lateral view. Anteroventrally, there is the long ischial symphysis. The anterior edge of the ischium is smoothly concave, forming the posterior border of the obturator foramen. The anteroventral corner has no evidence of contact with the pubic plate; this suggests the place is not completely ossified.

\section{Hindlimb}

The hindlimb is known in NCSM 20698. It includes the incomplete left femur, the left tibia, the proximal half of the left fibula, the nearly complete right fibula, and the articulated right pes. An articulated pes has only been reported in Exaeretodon (Bonaparte 1963) and 
337 NHMUK R9391, possibly Scalenodon (see discussion) (Jenkins 1971).

338 Femur. The femur is exposed in ventral and anteromedial views (Fig. 7A, C). It has a 339 moderately slender shaft and expanded articular end. The femur is straight for most of its length 340 but has a strong dorsomedially angle proximally. Due to this proximal dorsal bowing of the 341 proximal end of the shaft, the head, which is bulbous and almost hemispherical, is reflected 342 medially. The head bears rough texture typical of bone supporting a cartilaginous cap. There is a 343 crest connecting the head with the major trochanter, resulting in a semicircular outline for the 344 proximal end of the femur (Fig. 7C).

A deep intertrochanteric fossa lies on the ventral surface between the head and major trochanter and represents the point of insertion for the pubo-ischio-femoralis externus muscle.

Distal to the fossa, the minor trochanter runs distally along the ventral side of the shaft. It is a prominent flange that extends for about $6 \mathrm{~mm}$ and gradually merges into the bone at about midshaft. Distal to the minor trochanter, the anterior and the ventral surfaces of the femur are separated along an angular intersection. In cross-section, the shaft is nearly oval at mid-length; its thickness from the extensor to flexor surface is about $3.2 \mathrm{~mm}$ and its transverse width is 4.8 $\mathrm{mm}$.

Tibia. The left tibia is articulated with the proximal half of the fibula (Fig. 7A, C). It is almost only exposed in posterior view. The shaft of the tibia is flat and bowed medially. The proximal and distal ends are expanded mainly laterally so that the lateral margin is concave and the medial margin is slightly convex. Due to the poor ossification, the facets on the proximal articular end are not clearly defined. The lateral margin of this end is thickened and protuberant. The distal 
358

359

360

361

362

363

364

365

366

367

368

369

370

371

372

373

374

375

376

377

378

end terminates in a convex oval facet set at a right angle to the long axis of the shaft (Fig. 7C).

The bone is $22 \mathrm{~mm}$ in length, and its width is slightly more than $4 \mathrm{~mm}$ proximally and distally.

Fibula. The fibula has a slender shaft with expanded ends and is bowed laterally (Fig. 7A, C).

The proximal articular end is poorly ossified. The shaft is narrow proximally but gradually expands anteroposteriorly distally. The distal articular surface is oval in outline and convex. It contacts the concave articular surface formed by the calcaneum and astragalus.

Tarsus. The shape, number, and proportion of the tarsal elements (Fig. 7D) are similar to those in an unidentified cynodont from the Manda beds of Tanzania (NHMUK R9391) (Jenkins 1971).

The calcaneum is distoproximally elongate, but in contrast to NHMUK R9391, its distal head is slightly narrower than the proximal tuber calcis. A separate element seems to be present between the calcaneum and the astragalus. Based on the comparison with NHMUK R9391, it is identified as a process of the calcaneum. This stout process is about half of the width of the calcaneum and covers the astragalus ventrally. The sustentaculum tali lies dorsal and distal to the proximal facet for the astragalus, and a distinct calcaneal sulcus separates them. The calcaneum is constricted distally to form an articular surface exclusively for the cuboid.

The exact shape of the astragalus is unknown because it is covered by the calcaneum. It looks like a bean in ventral view. Its anterior edge is concave with a distal end that articulates with the navicular. The medial edge is slightly convex dorsomedially.

The navicular (centrale) is an irregular oval element. Its plantar surface is nearly flat or slightly convex. It articulates proximally with the astragalus and distally with the first, second, and third distal tarsalia (ento-, meso-, and ectocuneiforms) and probably with the fourth distal 
379

380

381

382

383

384

385

386

387

388

389

390

391

392

393

394

395

396

397

398

399

tarsal (cuboid) as well.

There are four distal tarsalia—entocuneiform, mesocuneiform, ectocuneiform, and

cuboid (from medial to lateral). The entocuneiform is nearly rectangular but its distal side is

slightly wider than the proximal side. It articulates distally with metatarsal I and laterally

(apparently) with metatarsal II. The mesocuneiform, the smallest of the tarsalia, is wedge-shaped.

Distally, it articulates with metatarsal II and proximally it has a short contact with the navicular.

The ectocuneiform is triangular in outline and articulates distally with metatarsal III. The cuboid

is smaller than the entocuneiform and similar to the navicular in size and shape. Distally it

articulates with metatarsal IV and possibly V, laterally with the ectocuneiform and possibly the

navicular, and proximally with the calcaneum.

Metatarsal. Four metatarsals are present but the distal end of the metatarsal I is missing (Fig.

7D). Metatarsals II, III, and IV are nearly similar in size and shape. Their distal ends are wider

than the proximal ends and the bones have slightly constricted shafts. The distoproximal lengths

are: II, $5.4 \mathrm{~mm}$; III, $6.2 \mathrm{~mm}$; IV, $6.0 \mathrm{~mm}$.

Phalanges. Only a few phalanges are preserved, so the digital formula is unknown (Fig. 7D). In

contrast with NHMUK R R9391 (Jenkins 1971), the proximal phalanges are long and dumbbellshaped with a median constriction. The lengths of these elements are close to those of the metatarsals.

(1)

COMPARISON AND DISCUSSION

The traversodontids are a diverse group including forms with skulls that range from a few 
400

401

402

403

404

405

406

407

408

409

410

411

412

413

414

415

416

417

418

419

420

centimeters in length to more than $40 \mathrm{~cm}$ (Huttenlocker 2014; Liu 2007). Their postcanine teeth

are highly variable in shape, which is the source for most of the diagnostic characters (Liu \&

Abdala 2014). The postcranial elements also show considerable variation among traversodontids.

Here we summarize the postcranial features from previous studies and personal observation.

\section{Axial skeleton}

Vertebral column. The number of vertebrae is poorly known in traversodontids due to poor preservation and/or insufficient preparation. The number of presacral vertebrae is 28 in Exaeretodon argentinus and E. riograndensis (Bonaparte 1963; Oliveira et al. 2007), possibly 26 (>23) in Massetognathus pascuali (Jenkins 1970b), at least 16 in Protuberum cabralense (Reichel et al. 2009), and 24 (>20) in Boreogomphodon. Among presacral vertebrae, seven cervicals are identified in the former two species, as well as in Thrinaxodon, Cynognathus (Jenkins 1971), and most extant mammals. The cervical vertebrae of traversodontids, as well as in all non-mammaliaform cynodonts with known cervical series (e.g., Kemp 1980b; Oliveira 2010), have cervical ribs. In mammals, the dorsal vertebral column is divided into a thoracic and lumbar series based on the conservation of articulated ribs in the former. Two series are also recognized in some cynodonts based on rib morphology (Jenkins 1970b, 1971). Because the rib morphology of the dorsal series varies among traversodontids, no common criterion is applicable. The sacral vertebrae are defined on the basis of their rib contact with the medial surface of the iliac blade. The number of sacral vertebrae varies from six or seven in Exaeretodon (Bonaparte 1963; Oliveira et al. 2007), three or four in Pascualgnathus (Bonaparte 1966) (Fig. 8C), six in Massetognathus pascuali, although the last ribs do not directly link to the iliac plate (Jenkins 
421

422

423

424

425

426

427

428

429

430

431

432

433

434

435

436

437

438

439

440

441

1970b), four in Andescynodon (Liu \& Powell 2009), and possibly four in Boreogomphodon.

Based on the current view of phylogenetic relationships (Liu \& Abdala 2014), the common

ancestor of traversodontids should have four sacral vertebrae. According to the presacral

vertebral count in known traversodontids, it is inferred that the presence of more than 20

presacrals is characteristic of traversodontids.

Ribs. Plesiomorphically simple ribs are generally retained in early synapsids, with complex ribs appearing in cynodonts. There is a diversity of rib morphology within the traversodontid cynodonts, with different types sometimes coexisting in the same individual.

The dorsal ribs in Traversodontidae can be divided into four basic types (Fig. 8). A Type I or 'normal' rib is one in which the shaft is slender with a slightly expanded proximal end (Fig. 8A). All ribs of Exaeretodon, Boreogomphodon and the anterior dorsal ribs of Massetognathus belong to this type. At least some Type I ribs are likely present in all traversodontid species. A Type II, tubercular rib, exhibits protuberances on its dorsal border (Fig. 8B). Type II is documented only in Protuberum (Reichel et al. 2009). A Type III rib is modified as costal plate. These ribs conform to a complex morphological gradient wherein the anteroposterior width of the plate and the shaft distal to the plate are variable in the same individual (Fig. 8C). This type is present in Andescynodon, Pascualgnathus, Luangwa, Menadon, Traversodon, and Protuberum (Barberena 1981; Bonaparte 1966; Kammerer et al. 2008; Kemp 1980a; Liu \& Powell 2009; Reichel et al. 2009). It is also present in the basal cynodonts Thrinaxodon and the basal Cynognathia, including Cynognathus, Diademodon, and trirachodontids. The presence of this rib type is considered plesiomorphic in traversodontids (Crompton 1955; Jenkins 1971). Compared to 
442 Thrinaxodon and trirachodontids (NMQR3521), the distal end of the costal plate does not form a

443 double-layered recurved surface. A Type IV rib is bifurcate with a Y-shaped distal end (Fig. 8D).

444 Type IV is only known at the posterior end of the dorsal series in Massetognathus (Jenkins

445 1970b; Pavanatto et al. 2015).

446 Anterior dorsal ribs of traversodontids do not bear costal plates as in Cynognathus,

447 Diademodon, and triracodontids, whereas the posterior dorsal ribs are represented by costal

448 plates in most genera, except Massetognathus, Exaeretodon, and Boreogomphodon. The

449 posterior dorsal ribs are generally shorter than the anterior dorsal ribs, but the transformation in

450 length is smooth in most species and no clear differentiation on thoracic and lumbar region can

451 be made possible other than in Massetognathus. Jenkins (1971, p55) identified the first lumbar

452 vertebra in Thrinaxodon on the basis of the loss of a rib shaft distal to the costal plate. In

453 traversodontids with type III ribs, this criterion can be applied (e.g., Kemp 1980).

454 Generally, sacral ribs are similar in length and have a distal expansion to connect with the

455 iliac blade. However, in Massetognathus pascuali, the first sacral rib (Jenkins, 1970b: fig. 2A, S1)

456 is similar in shape to the last lumbar, and the last sacral rib (Jenkins, 1970b: fig. 2A, S6) is too

457 short to contact the iliac blade (Jenkins 1970b). The first sacral rib has a more expanded distal

458 end than subsequent ones. The caudal ribs are synostosed to the vertebrae and their shafts direct

459 posterolaterally.

460 NHMUK R9391 from the Manda Formation is associated with bones of the

461 probainognathian Aleodon and of a few traversodontid species. This specimen only features

462 Type III ribs (Fig. 8E). These ribs are essentially similar to the posterior dorsal ribs of 
463 Andescynodon and Pascualgnathus. Because this form of rib is unknown in Probainognathia, it

464 is considered here to be diagnostic of traversodontids..

465 Jenkins (1971) reviewed the epaxial muscles in reptiles and mammals, associating the costal

466 plates in cynodonts with a well-developed iliocostalis muscle. He suggested two functions for

467 them. The first is related to locomotion. The coastal plates would have provided larger

468 insertional area for attachment of the muscle; and assisted the lateral flexure of the vertebral

469 column. The second function would be the provision of intrinsic strength to the vertebral column

470 by the imbrication of successive ribs. He connected this function with the reinforcement of

471 lumbar region of mammals, which promote the ability of transmit thrust force. Kemp (1980)

472 analyzed function of the costal ribs in Luangwa. He suggested that Luangwa has no lateral

473 movement of the vertebral column because vertebral column is effectively rigid in this plane. He

474 proposed two advantages: the first one is maintenance of the momentum; the second one is the

475 improvement on the maneuverability. However, the curled skeletons of Thrinaxodon such as

$476 \mathrm{BP} / 1 / 2776$ indicate the presence of a considerable lateral movement of the vertebral column even

477 if it has costal plates.

478 In mammals, xenarthrous vertebrae are perhaps an adaptation for fossorial behavior (Gaudin

479 \& Biewener 1992). Expanded ribs may increase the stability of the vertebral column, and are a

480 common character in fossorial mammals (Jenkins 1970a). Groenewald et al. (2001) showed that

481 Trirachodon excavated burrows, and Damiani et al. (2003) demostrated that Thrinaxodon

482 inhabited burrows too. Trirachodon and Thrinaxodon have both costal plates and anapophyses.

483 The anapophyses are associated to Type III ribs in all known traversodontids; this perhaps 
484 suggests a fossorial behavior for these species. In Massetognathus, the zygapophyseal facets on 485 posterior dorsals are oriented at angles of around $45^{\circ}$ but the anapophyses are absent. So the 486 bending both in lateral and dorsoventral directions is permitted. The posterior process on 487 posterior dorsal ribs maintains the tendency of reinforcement of the lumbar region but reduced to 488 a lighter structure to acquire higher mobility. Although the ribs of Protuberum are special in the presence of dorsal tubercles, the basic pattern is the same as that of other traversodontids with Type I ribs. In Protuberum, the posterior dorsal ribs have larger costal plates than other traversodontids; they overlap each other to form a connected plate. This is the most rigid vertebral column in the group and must have provided increased protection for the internal organs. The surface tubercles perhaps indicate defensive structures. On the other hand, the similar sized Exaeretodon adopted another strategy as their ribs are reduced to normal costal type

I. Perhaps only Boreogomphodon has a truly lumbar region in all known traversodontids. The lumbar vertebrae, and possibly all dorsal vertebrae, can rotate in sagittal and horizontal planes, indicating that the vertebral column was able to bend laterally and dorsoventrally. The lumbar vertebrae are more massive than thoracic vertebrae.

Shoulder girdle

Interclavicle and clavicle. The interclavicle and the clavicle are known only in Exaeretodon argentinus (Fig. 9A, B; Bonaparte, 1963: fig.16), Massetognathus pascuali (Fig. 9C, D; Jenkins 1970a: fig. 5), and Boreogomphodon (Fig. 4); the clavicle is also reported in Andescynodon (Liu \& Powell 2009) and Pascualgnathus (Bonaparte 1966). As in Thrinaxodon (Jenkins, 1971), the interclavicle of Boreogomphodon and Massetognathus is cruciate with an elongate posterior 
505

506 similar to the length. No notable difference in the clavicle has been observed between

507 traversodontid species.

508 Scapulocoracoids. Other than Boreogomphodon, the scapulocoracoids were reported in 509

ramus. In Exaeretodon, it is laterally expanded with a short posterior ramus, so the width is Andescynodon (Liu \& Powell 2009), Exaeretodon (Bonaparte 1963), Luangwa (Kemp 1980a), Massetognathus (Jenkins 1970b; Pavanatto et al. 2015), Menadon (Kammerer et al. 2008), Pascualgnathus (Bonaparte 1966), and Traversodon (von Huene 1936-42) (Fig. 10).

In Cynognathus and Diademodon, the scapula is not constricted below the acromion process and the anteroposteriorly shorter portion lies above the acromion process (Jenkins, 1971: fig. 17; Fig 10A-D). In Traversodontidae, the scapular blade is constricted below the acromion process, forming an anteroposteriorly short neck (Fig. 10) that provides extra space for the insertion of the supracoracoideus muscle. Kemp (1980) described the acromion process of Luangwa as more reflected laterally than that of Diademodon-Cynognathus (Fig. 10A, C, I). This condition is represented in all traversodontids with well-preserved scapula. The acromion process is reconstructed very high in the scapula of Pascualgnathus (Fig. 10E; Bonaparte 1966). However, that portion of the bone is poorly preserved in the specimen and here is interpreted as part of the scapular flange based on personal observation.

The procoracoid participates into the glenoid in Luangwa and Pascualgnathus (Fig. 10E, J); it reaches but does not participate in the glenoid in Massetognathus, Menadon, and perhaps Andescynodon (Fig. 10G, K-N); and it is far from the glenoid in Exaeretodon, Boreogomphodon, and Traversodon (Fig. 10F, H, O, P). 
526 The shape of the procoracoid is variable within this group. The ventral margin of

527 procoracoid is confluent with that of coracoid, forming a convex flange in Andescynodon, 528 Massetognathus, Menadon, possibly in Boreogomphodon and Pascualgnathus; while it is

529 roughly straight in Luangwa. The anterior margin of the procoracoid is convex in Luangwa, and

530 Menadon as in Cynognathus and Diademodon, nearly straight or slight concave in Andescynodon,

531 Boreogomphodon, and perhaps Exaeretodon and Massetognathus.

532 The procoracoid foramen is close to the articular surface with the scapula in this group,

533 whereas it lies in the anterior corner of the bone, far from the articular surface with the scapula in

534 Cynognathus (Fig 10A, B). It is closer to the articular surface with the coracoid than the anterior margin in Luangwa, Massetognathus (contra Jenkins 1970b: fig. 6), and Menadon whereas it is closer to the anterior margin of the bone in Exaeretodon (PVL 2554) and Boreogomphodon. process ends in a tuberosity. The tuberosity is short and mainly ventral to the glenoid in Luangwa, Traversodon, and possibly Exaeretodon; but long and distinctly posterior to the glenoid in Andescynodon, Pascualgnathus, Massetognathus, and Menadon. The dorsomedial margin of the coracoid is shorter than that of the procoracoid in Luangwa and possibly

Pascualgnathus, nearly equal to that of Massetognathus and Menadon, and is longer than that of

Boreogomphodon and perhaps in Andescynodon.

\section{Forelimb}

545 Humerus. The humeri are preserved in many species. The basic shape is the same in this group 546 as in Cynognathus or Diademodon (Fig. 11). The proximal half of the humerus is roughly 
547 triangular in most species, whereas it is roughly trapezoid in Exaeretodon for the development of

548 a flange on the posteromedial surface. The articular surface is confluent medially with the lesser

549 tuberosity and laterally with the proximal margin of the deltopectoral flange. The lesser

550 tuberosity is better developed in Luangwa than in other species. The deltopectoral crest reflects

551 laterally in different degrees but this structure is easily deformed during fossilization, and it is

552 uncertain how much of the observed difference is due to deformation.

553 The relative width of the humerus varies with the length (Table 1). The basic functions of the

554 bones are the support of the body against gravity and to attach the muscles. The diameter (width)

555 of a supporting bone as the humerus should increase with the increase of length (Christiansen

556 1999); this is shown by the positive allometry of the proximal width (PW), the distal width (DW),

557 and the sum of the shaft minimum width in anteroposterior and dorsoventral directions (S1+S2)

558 relative to the length (L) (Fig. 12). The scaling is close to 1.2 other than the one related to the

559 distal width. The regression function for $\mathrm{L}(\mathrm{Y})$ to $\mathrm{S} 1+\mathrm{S} 2(\mathrm{X})$ is: $\mathrm{Y}=5.7695 \mathrm{X}^{0.833}\left(\mathrm{R}^{2}=0.984\right)$. In

560 the mammalian humerus, the scaling for the least circumference to the length is 0.76 for all

561 mammals, 0.83 for small mammals under least squares regression (Christiansen 1999). Here, the

562 sum of S1 and S2 can be used as a lineal approximation of the least circumference, so this

563 scaling $(0.83)$ can be compared with that of small mammals. This scaling $\left(l \infty d^{0.83}\right)$ is

564 intermediate between geometric similarity (isometry: $100 \mathrm{~d})$ and elastic similarity $\left(l 00 d^{0.67}\right)$, far

565 from stress similarity $\left(l \infty d^{0.5}\right)$ (Christiansen 1999). It shows that the humeral growth strategy is

566 similar to that of small mammals. The point of Luangwa appears to be an outlier (Fig. 12);

567 indicating that its shaft is slenderer than the normal humerus. 
568 Ulna and radius. As the humerus, the ulna and the radius are robust in large specimen and

569 slender in small specimens. The inter-specific difference is distinct on the proximal side of the

570 ulna (Fig. 13). The ossified olecranon process is absent in all but Exaeretodon, in which the

571 relative length of the olecranon is about fifteen percent of remaining portion of the ulna (MACN

572 18063, PVL 2467) (Bonaparte 1963). The length of the ulna is about $68 \%$ of the humerus in two

573 specimens of Boreogomphodon, the ratio of ulna/humerus in Exaeretodon, Massetognathus, or

574 Pascualgnathus is greater than $76 \%$ (Table 2). If the olecranon portion is excluded, the ratio in

575 Exaeretodon (PVL2467) is similar to that of Boreogomphodon.

576 Manus. The manus is only known in Boreogomphodon and Exaeretodon (Bonaparte 1963, fig.

577 20). Most carpals are identified in both species, except for the fifth distal carpal in Exaeretodon,

578 and the pisiform in Boreogomphodon. The pisiform is a large element in Thrinaxodon and

579 Diademodon (Jenkins, 1971, p127), but smaller in Exaeretodon. Even if this bone was ossified in

Boreogomphodon, it would have been too small to be observed. Besides Boreogomphodon, a separate fifth distal carpal is only known in one specimen of Thrinaxodon among non mammaliaform cynodonts (Jenkins 1971; Parrington 1933). When present, the fifth is the smallest of the distal carpals. It is lost or fused in Exaeretodon. The digital formula of

Exaeretodon is 2-3-3-3-3; whereas the preserved elements in Boreogomphodon are 2-1-3-3-3.

Because Cynognathus, Diademodon, and Cricodon also have a digital formula of 2-3-3-3-3, it is safe to infer this formula is conserved among all cynognathians, including Boreogomphodon 587 (Crompton 1955). 
588

589

590

591

592

593

594

595

596

597

598

599

600

601

602

603

604

605

606

607

608

\section{Pelvis}

The pelvis was described in Andescynodon (Liu \& Powell 2009), Exaeretodon (Bonaparte 1963), Luangwa (Kemp 1980a), Massetognathus (Jenkins 1970b; Pavanatto et al. 2015), Menadon (Kammerer et al. 2008), Pascualgnathus (Bonaparte 1966), and NHMUK R9391 (Jenkins 1971) (Fig. 14).

The ilium in traversodontids is clearly different from that of Cynognathus or Diademodon (Jenkins 1971). The dorsal (vertebral) margin is nearly straight or slightly concave rather than convex in all well-preserved ilia. In a trirachodontid (NMQR 3521), this part looks still convex (Fig. 14I). The angle between the ventral margin of the anterior and posterior processes of the iliac blade is around $120^{\circ}$ in NHMUK R9391 and Pascualgnathus, about $150^{\circ}$ in Andescynodon, Luangwa, Massetognathus, and Menadon, nearly $180^{\circ}$ in Exaeretodon; so the neck between the blade and the base is narrower and more obvious in NHMUK R3521 and Pascualgnathus. In Cynognathus and Diademodon, the neck is wide and short as Massetognathus; but in a trirachodontid (NMQR 3521), the neck is narrow and pronounced as in Pascualgnathus (Fig. $14 \mathrm{H})$. In traversodontids, the ventral margin of the anterior process of the blade is nearly parallel to the dorsal margin. The anterior part of the blade is narrowly rounded and somewhat spoonshaped, with the exception of Exaeretodon where the anterior part is widely rounded and axshaped (Fig. 14G). The anterior process is short in NHMUK R9391 (less than the diameter of the acetabulum), relatively long in Pascualgnathus (between 1 to 1.5 times of the diameter of the acetabulum), and long in other species (greater than 1.5 times of the diameter of the acetabulum).

The posterior process is long in all known species other than Exaeretodon, where its length is 
609

610

611

612

613

614

615

616

617

618

619

620

621

622

623

624

625

626

627

628

629

less than the diameter of the acetabulum.

The morphological features of the ilium and the rib of NHMUK R9391 show this specimen representing a traversodontid species with primitive characters. Two genera, Scalenodon and Mandagomphodon, have been referred to Traversodontidae based on materials from the Manda Formation (Crompton 1972; Hopson 2014; Liu \& Abdala 2014). Within their named species, $S$. angustifrons is far more basal than other species. If we accept the correlation of skull and postcranial features, this specimen could be referred to $S$. angustifrons.

The lateral surface of the blade is concave, forming a fossa, which lies mainly on the anterior process. The anterior process in Luangwa and Massetognathus features a laterally reflected ventral margin (Kemp, 1980; Liu, pers. obs: PVL 4442) that enhance the fossa on the anterior process. With the shape of iliac blade of Exaeretodon, the center of the fossa is close to the anterior margin of the blade. We interpret this fossa as the origin for ilio-femoralis (gluteal) muscle. Jenkins (1971) did not observe muscle markings on the lateral surface of iliac blade in Cynognathus, and he suggested that the origin of the ilio-femoralis (gluteal) muscle was in the fossa anterodorsal to the acetabulum. Kemp (1980) disagreed, suggesting this muscle occupied most of the lateral surface of the iliac blade in Luangwa. With the extension of the anterior process, and the anterior position of the fossa as in Exaeretodon, the muscle is disposed more horizontally and enjoys a greater volume, which results in an increased retraction force on the femur. 
630 is nearly horizontal. This placement is probably reconstructed following the conditions 631 represented in Thrinaxodon (AMNH 2228) and Diademodon (USNM 23352) where the pelvis is 632 preserved in situ. Meanwhile, Bonaparte (1963: fig. 21) reconstructed the iliac blade as being 633 more posteriorly inclined in Exaeretodon; Bonaparte (1966: fig. 15) and Kemp (1980: fig. 13) 634 represented the ilium anteriorly inclined in Pascualgnathus and Luangwa, respectively. The exact original position of the ilium is difficult to infer, but the axis of the attaching points of the ribs on the iliac blade should form a small angle with the horizontal (Fig. 14).

Based on the reconstructed posture, the pubis extends anteriorly beyond the anterior margin of the acetabulum in Scalenodon, Andescynodon, and Pascualgnathus, and ventral to the acetabulum, without reaching its anterior margin, in Luangwa, Massetognathus, Menadon, and

Exaeretodon. The pubis generally is ventrally and medially directed, but is almost medially directed in Luangwa. The diameter of the obturator foramen is similar to the diameter of the acetabulum in Scalenodon, Andescynodon, Pascualgnathus, and Massetognathus, smaller in

Exaeretodon, and perhaps larger in Luangwa.

\section{Hindlimb}

As major supporting bones, the diameters of the femur, tibia, and fibula increase with length, so they are slender in small specimens and more massive in large ones (Table 3).

Femur. The basic structure of the femur in traversodontids is similar to that of Cynognathus (Fig. 15). The robust major trochanter generally is confluent with the head forming a semicircular outline to the proximal side of the bone. A notch separates the head from the trochanter major in 
651 ochagaviae (Pavanatto et al., 2015: fig. 7). The notch could be the result of poor ossification or 652 preservation, at least in Andescynodon. Kemp (1980) described the major trochanter of Luangwa 653 as extending further proximally than in Cynognathus-Diademodon; however, the position of the 654 major trochanter is similar between them and differs from most tranversodontids in being 655 slightly more distal and lateral (Jenkins, 1971: fig.48). The minor trochanter is mostly directed 656 posteriorly and slightly medially in Boreogomphodon, Massetognathus, Pascualgnathus, 657 Scalenodon angustifrons, and Traversodon, but is directed strongly medially in Andescynodon, 658 Exaeretodon, and Luangwa. This morphology in the latter taxon could be accentuated by 659 deformation.

660 Pes. The tarsus is well preserved in Scalenodon (NHMUK R9391), Boreogomphodon (NCSM 661 20698), and Exaeretodon (PVL 2554). Seven tarsals are observed in the two former species, 662 whereas one more is present in Exaeretodon (Bonaparte 1963; Jenkins 1971). Metatarsal I is the 663 shortest in all cases. The digital formula is interpreted as 2-3-3-3-3 for this group. presacral vertebrae including 7 cervicals; at least 4 sacrals; interclavicle cruciate with an elongate posterior ramus; scapula is distinctly constricted at the base of the acromion process, forming a neck; iliac dorsal margin nearly straight or slightly concave; major trochanter of femur robust; manus and pes digital formula $2-3-3-3-3$. Variation is more extensive in the axial skeleton than in

671 the pelvis and pectoral girdle. There are some important variations in the limbs. The vertebrae 
672 mainly differ in the number of sacral vertebrae, the presence of the anapophyses, and the angle of

673 zygophyseal facets. The ribs in most species preserve the primitive morphology of Diademodon

674 and trirachodontids while the ridge on costal plates is reduced. The structure of ribs is further

675 reduced in some species like Boreogomphodon, Massetognathus, and Exaeretodon; but is

676 complicated in Protuberum. The acromion process and the scapular neck are well developed in

677 this group, but the relatively long neck only occurred in Boreogomphodon. The major

678 transformation in shoulder girdle is the reduced size of the procoracoid. The anterior process of

679 the iliac blade extends anteroventrally in this group, and the iliac neck is less pronounced than in

680 the primitive member Pascualgnathus; the posterior process shows no distinct change other than

681 the shortening in Exaeretodon. The structure of the limb bones is relatively uniform, and the

682 robustness of the limb bones is directly related to their size.

683 The relative uniformity of the structures indicates similar locomotory strategies in this

684 group. The humerus still moves in a horizontal plane, and the femur is half-erect. The anterior

685 position of the iliac blade enables more efficient rotation of the femur in a nearly erect gait. The

686 vertebral column is rigid but permits bending in most species, being more flexible in derived 687 forms.

Institutional abbreviations

690 AMNH American Museum of Natural History, New York, NY, USA

691 BP Evolutionary Studies Institute, University of the Witwatersrand, Johannesburg, 


\author{
693 GPIT Institut und Museum für Geologie und Paläontologie der Universität Tübingen,

\title{
ACKNOWLEDGEMENTS
}

The cooperation and hospitality of the staff of various museums and institutions greatly

Museum of Natural History, UK); the late Ray Symonds (University Museum of Zoology, and Bruce Rubidge (Evolutionary Studies Institute, Johannesburg, South Africa); Jennifer Botha-

710 Brink and Elize Butler (National Museum, Bloemfontein, South Africa); Roger Smith and

711 Sheena Kaal (Iziko Museums-South African Museum, Cape Town, South Africa); Johann

712 Neveling (Council for Geosciences, Pretoria, South Africa); Stephany Potze (Transvaal Museum,

713 South Africa); Ana Maria Ribeiro (Museu de Ciências Naturais, Fundação Zoobotânica do Rio 
714 Grande do Sul, Porto Alegre, Brazil); Maria C. Malabarba (Museu de Ciências e Tecnologia,

715 Pontificia Universidade Católica do Rio Grande do Sul, Porto Alegre, Brazil); Marina B. Soares

716 and Cesar L. Schultz (Universidade Federal do Rio Grande do Sul, Porto Alegre RS, Brazil);

717 Jaime E. Powell (Universidad Nacional de Tucumán, Argentina); Alejandro Kramarz and

718 Agustín G. Martinelli (Museo Argentino de Ciencias Naturales "Bernardino Rivadavia”, Buenos

719 Aires, Argentina); Guillermo F. Vega (Museo de Antropología, Universidad Nacional de La

720 Rioja, Argentina); Ricardo Martinez (Museo de Ciencias Naturales, Universidad Nacional de

721 San Juan, Argentina); Marcelo Reguero and Rosendo Pascual (Museo de La Plata, Argentina);

722 Charles R. Schaff (Museum of Comparative Zoology, Harvard University, Cambridge,

723 Massachusetts, USA), Hans-Dieter Sues and Matthew Carrano (National Museum of Natural

724 History, Washington, D.C., USA), James A. Hopson (University of Chicago, Chicago, USA),

725 Olivier Rieppel, Elaine Zeiger, and William F. Simpson (Field Museum of Natural History,

726 Chicago, USA); and John Flynn (American Museum of Natural History, New York, USA).

727 Fernando Abdala and Hans-Dieter Sues read the draft and gave helpful comments; Christian

728 Kammerer and Leandro Gaetano reviewed the manuscript. Christian Kammerer kindly provided

729 some photos. Gabe Bever improved the writing.

\section{REFERENCES}

Abdala F, and Ribeiro AM. 2010. Distribution and diversity patterns of Triassic cynodonts (Therapsida, Cynodontia) in Gondwana. Palaeogeography, Palaeoclimatology, Palaeoecology 286:202-217. 
737

738

739

740

741

742

743

744

745

746

747

748

749

750

751

752

753

754

755

756

757

758

759

760

761

762

763

764

765

766

767

768

769

770

771

772

773

774

775

776

777

Bonaparte JF. 1963. Descripción del esqueleto postcraneano de Exaeretodon (Cynodontia Traversodontidae). Acta Geológica Lilloana 4:5-52.

Bonaparte JF. 1966. Una nueva 'fauna' triásica de Argentina (Therapsida: Cynodontia Dicynodontia). Consideraciones filgenéticas y paleobiogeográficas. Ameghiniana 4:243-296.

Christiansen P. 1999. Scaling of the limb long bones to body mass in terrestrial mammals. Journal of Morphology 239:167-190.

Crompton AW. 1955. On some Triassic cynodonts from Tanganyika. Proceedings of the Zoological Society of London 125:617-669.

Crompton AW. 1972. Postcanine occlusion in cynodonts and tritylodontids. Bulletin of the British Museum (Natural History), Geology 21:29-71.

Damiani R, Modesto S, Yates A, and Neveling J. 2003. Earliest evidence of cynodont burrowing. Proceedings of the Royal Society of London Series B-Biological Sciences 270:1747-1751.

Gaudin TJ, and Biewener AA. 1992. The Functional Morphology of Xenarthrous Vertebrae in the Armadillo Dasypus novemcinctus (Mamrnalia, Xenarthra). Journal of Morphology 214:63-81.

Groenewald GH, Welman J, and MacEachern JA. 2001. Vertebrate burrow complexes from the early Triassic Cynognathus zone (Driekoppen Formation, Beaufort Group) of the Karoo Basin, South Africa. Palaios 16:148-160.

Hopson JA. 2014. The Traversodontid Cynodont Mandagomphodon hirschsoni from the Middle Triassic of the Ruhuhu Valley, Tanzania. In: Kammerer CF, Angielczyk KD, and Fröbisch J, eds. Early Evolutionary History of the Synapsida. New York: Springer, 233253.

Hopson JA, and Kitching JW. 2001. A probainognathian cynodont from South Africa and the phylogeny of nonmammalian cynodonts. Bulletin of the Museum of Comparative Zoology 156:5-35.

Huttenlocker AK. 2014. Body size reductions in nonmammalian eutheriodont therapsids (Synapsida) during the end-Permian mass extinction. PLoS ONE 9:e87553.

Huttenlocker AK, Sidor CA, and Angielczyk KD. 2015. A new eutherocephalian (Therapsida, Therocephalia) from the upper Permian Madumabisa Mudstone Formation (Luangwa Basin) of Zambia. Journal of Vertebrate Paleontology 35 :e969400.

Jenkins FA, Jr. 1970a. Anatomy and Function of Expanded Ribs in Certain Edentates and Primates. Journal of Mammalogy 51:288-301.

Jenkins FA, Jr. 1970b. The Chañares (Argentina) Triassic reptile fauna; VII, The postcranial skeleton of the traversodontid Massetognathus pascuali (Therapsida, Cynodontia). Breviora 352:1-28.

Jenkins FA, Jr. 1971. The postcranial skeleton of African cynodonts; problems in the early evolution of the mammalian postcranial skeleton. Bulletin - Peabody Museum of Natural History 36:1-216.

Kammerer CF, Flynn JJ, Ranivoharimanana L, and Wyss R. 2008. New material of Menadon besairiei (Cynodontia: Traversodontidae) from the Triassic of Madagascar. Journal of 
Vertebrate Paleontology 28:445-462.

Kammerer CF, Fröbisch J, and Angielczyk KD. 2013. On the validity and phylogenetic position of Eubrachiosaurus browni, a kannemeyeriiform dicynodont (Anomodontia) from Triassic North America. PLoS ONE 8:e64203.

Kemp TS. 1980a. Aspects of the structure and functional anatomy of the Middle Triassic cynodont Luangwa. Journal of Zoology 191:193-239.

Kemp TS. 1980b. The primitive cynodont Procynosuchus; structure, function and evolution of the postcranial skeleton. Philosophical Transactions of the Royal Society of London, Series B: Biological Sciences 288:217-258.

Liu J. 2007. The taxonomy of traversodontid cynodonts Exaeretodon and Ischignathus. Revista Brasileira de Paleontologia 10:133-136.

Liu J, and Abdala F. 2014. The phylogeny and taxonomy of Traversodontidae. In: Kammerer CF, Angielczyk KD, and Fröbisch J, eds. Early Evolutionary History of the Synapsida. New York: Springer, 255-279.

Liu J, and Olsen PE. 2010. The phylogenetic relationships of Eucynodontia (Amniota: Synapsida). Journal of Mammalian Evolution 17:151-176.

Liu J, and Powell J. 2009. Osteology of Andescynodon (Cynodontia: Traversodontidae) from the Middle Triassic of Argentina. American Museum Novitates 3674:1-19.

Liu J, and Sues H-D. 2010. Dentition and tooth replacement of Boreogomphodon (Cynodontia: Traversodontidae) from the Upper Triassic of North Carolina, USA. Vertebrata Palasiatica 48:169-184.

Oliveira TV, Schultz CL, and Soares MB. 2007. O esqueleto pós-craniano de Exaeretodon riograndensis Abdala et al. (Cynodontia, Traversodontidae), Triássico do Brasil. Revista Brasileira de Paleontologia 10:79-94.

Oliveira TV, Soares MB, and Schultz CL. 2010. Trucidocynodon riograndensis gen. nov. et sp. nov. (Eucynodontia), a new cynodont from the Brazilian Upper Triassic (Santa Maria Formation). Zootaxa 2382:1-71.

Parrington FR. 1933. On the cynodont reptile Thrinaxodon liorhinus Seeley. Annals and Magazine of Natural History 10/xi:16-24.

Pavanatto AEB, Müller RT, Da-Rosa ÁAS, and Dias-da-Silva S. 2015. New information on the postcranial skeleton of Massetognathus ochagaviae Barberena, 1981 (Eucynodontia, Traversodontidae), from the Middle Triassic of Southern Brazil. Historical Biology:1-12.

Reichel M, Schultz C, and Soares MB. 2009. A new traversodontid cynodont (Therapsida, Eucynodontia) from the Middle Triassic Santa Maria Formation of Rio Grande do Sul, Brazil. Palaeontology 52:229-250.

Sues H-D, and Hopson JA. 2010. Anatomy and phylogenetic relationships of Boreogomphodon jeffersoni (Cynodontia: Gomphodontia) from the Upper Triassic of Virginia. Journal of Vertebrate Paleontology 30:1202-1220.

Sues HD, and Olsen PE. 1990. Triassic vertebrates of Gondwanan aspect from the Richmond Basin of Virginia. Science 249:1020-1023.

Sues HD, Olsen PE, and Carter JG. 1999. A late Triassic traversodont cynodont from the 
819 Newark Supergroup of North Carolina. Journal of Vertebrate Paleontology 19:351-354.

820 von Huene FF. 1936-1942. Die fossilen Reptilien des südamerikanischen Gondwanalandes.

821 Ergebnisse der Sauriergrabungen in Südbrasilien, 1928/1929. Munchen: C. H. Beck. 
Figure 1

Boreogomphodon (NCSM 20711), cervical vertebrae and ribs 2 to 5 in lateral view.

Abbreviations: 2-5, cervical 2-5; d, dentary; cl, clavicle; cr, cervical rib; ns, neural spine; pp, posterior process. Scale bar equals $1 \mathrm{~cm}$.
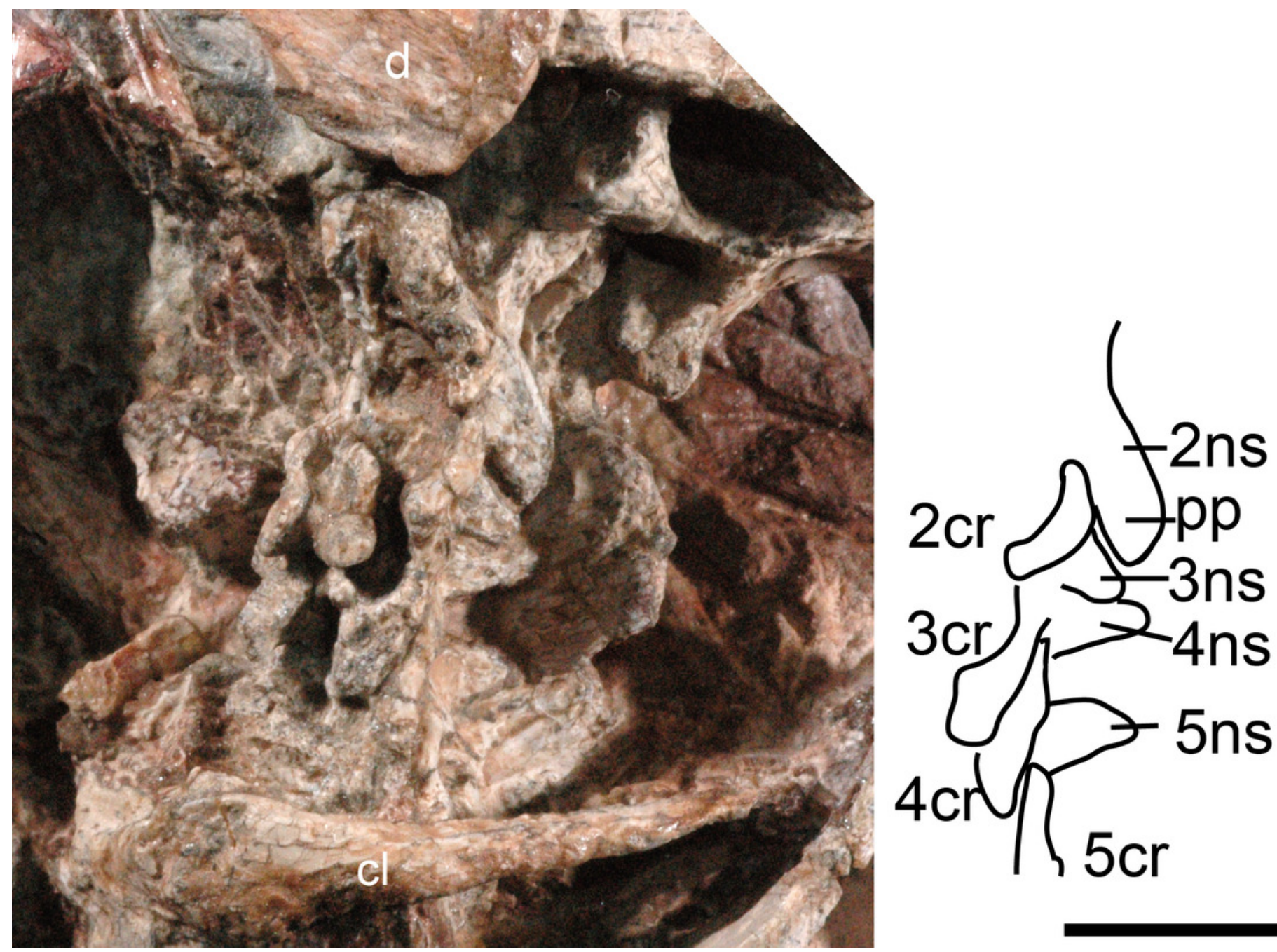
Figure 2

Boreogomphodon (NCSM 20698), anterior dorsal vertebrae and ribs.

In $(A)$ ventral and $(B)$ ventrolateral views, the anterior is right; posterior dorsal vertebrae in (C) dorsal, (D) left lateral and (E) ventral views, the anterior is left. Two parts form a continue series. Scale bars equal $1 \mathrm{~cm}$.

*Note: Auto Gamma Correction was used for the image. This only affects the reviewing manuscript. See original source image if needed for review. 


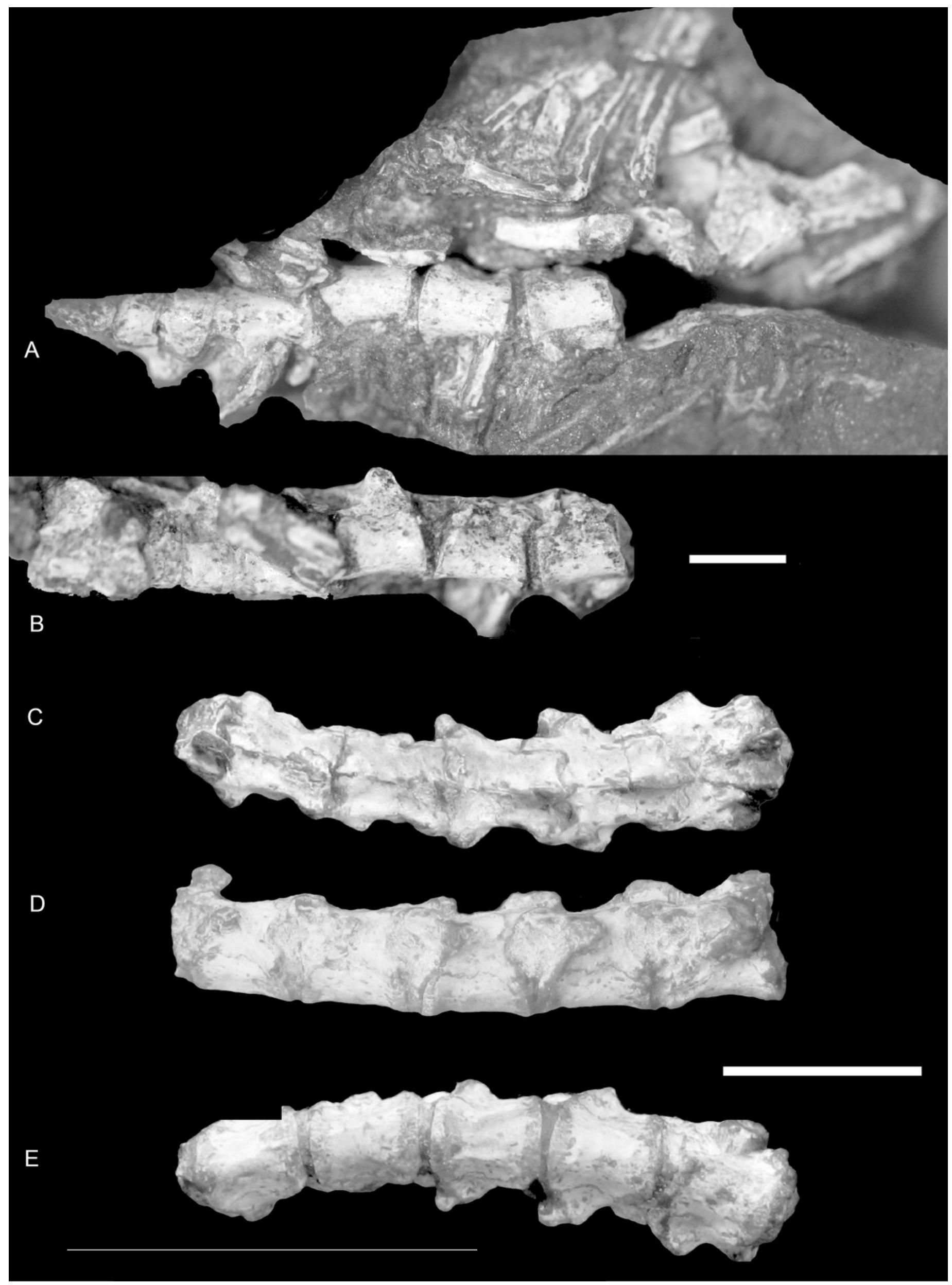




\section{Figure 3}

Boreogomphodon (NCSM 20698), posterior dorsal, sacral and anterior caudal vertebrae and ribs.

In (A) ventrolateral and (B) ventral views; the left ischium in lateral view. Anterior is right. Abbreviations: dr, dorsal rib; poz, postzygapophysis; prez, prezygapophysis; sr, sacral rib; sv, sacral vertebra. Scale bar equals $5 \mathrm{~mm}$.

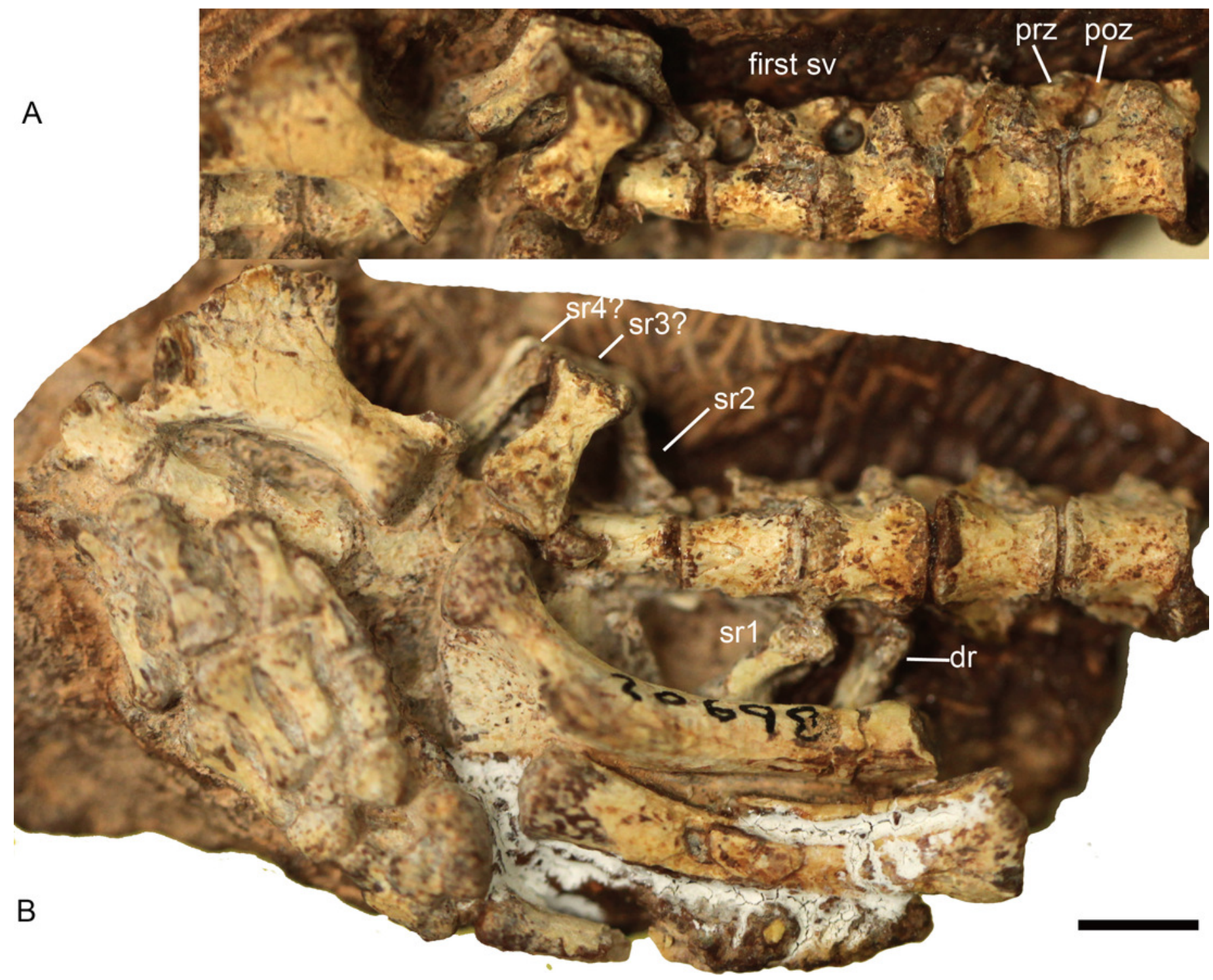




\section{Figure 4}

Boreogomphodon, shoulder girdles.

(A) NCSM 20711 mainly in ventral view. NCSM 20698, left scapula in (B) lateral, (C) posterior, and (D) medial views; (E) right procoracoid in lateral view. Abbreviations: acr, acromion; ar, anterior ridge; bi, fossa for origin of biceps muscle; $\mathrm{C}$, clavicle; $\mathrm{cb}$, fossa for origin of coracobrachialis muscle; cc, concavity for articulation with medial end of clavicle; COR, coracoid; $d$-t min, insertion for deltoideus plus teres minor muscle complex; $f$ prc, procoracoid foramen; $\mathrm{H}$, humerus; IC, interclavicle; Ir, lateral ridge; pr, posterior ridge; PRC, procoracoid; prc (cor), procoracoid articular surface for coracoid; prc (s), procoracoid articular surface for scapula; S, scapula; spc, fossa for supracoracoideus muscle. Scale bars equal $5 \mathrm{~mm}$.

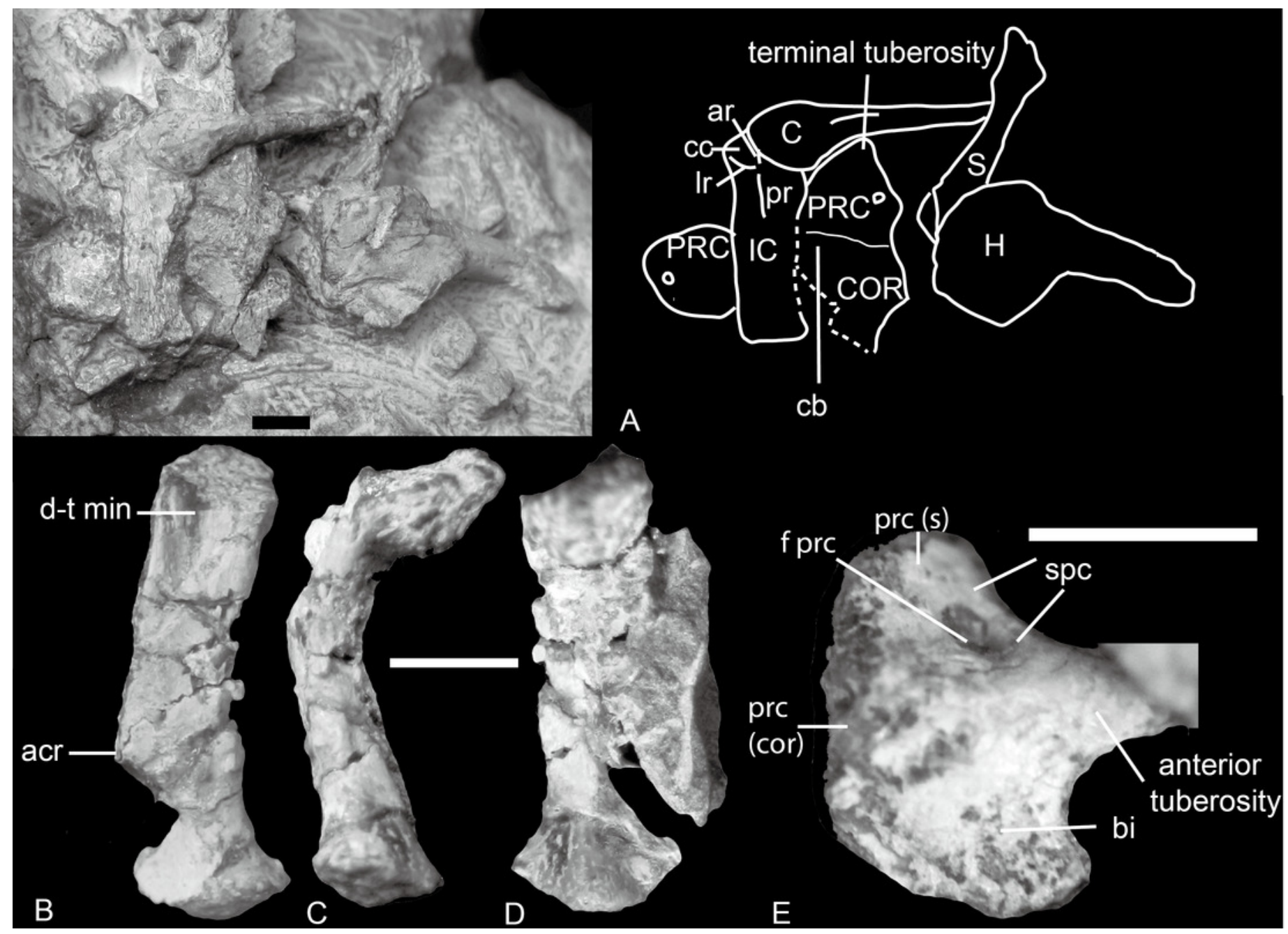




\section{Figure 5}

Boreogomphodon, humeri.

Right humerus (NCSM 20698) in (A) ventral, (B) anterior (lateral), (C) dorsal, and (D), posterior (medial) views; distal part of left humerus (NCSM 21370) in (E) ventral, (F) distal, and (G) dorsal views. Abbreviations: bi gr, bicipital groove; $c p$, capitulum; d c, deltopectoral crest; ec, ectepicondyle; en, entepicondyle; f en, entepicondylar foramen; $\mathrm{gt}$, greater tuberosity; h, humeral head; I t lesser tuberosity; sc $\mathrm{f}$, supracondylar flange; th, trochlea. Scale bar equals $1 \mathrm{~cm}$. 


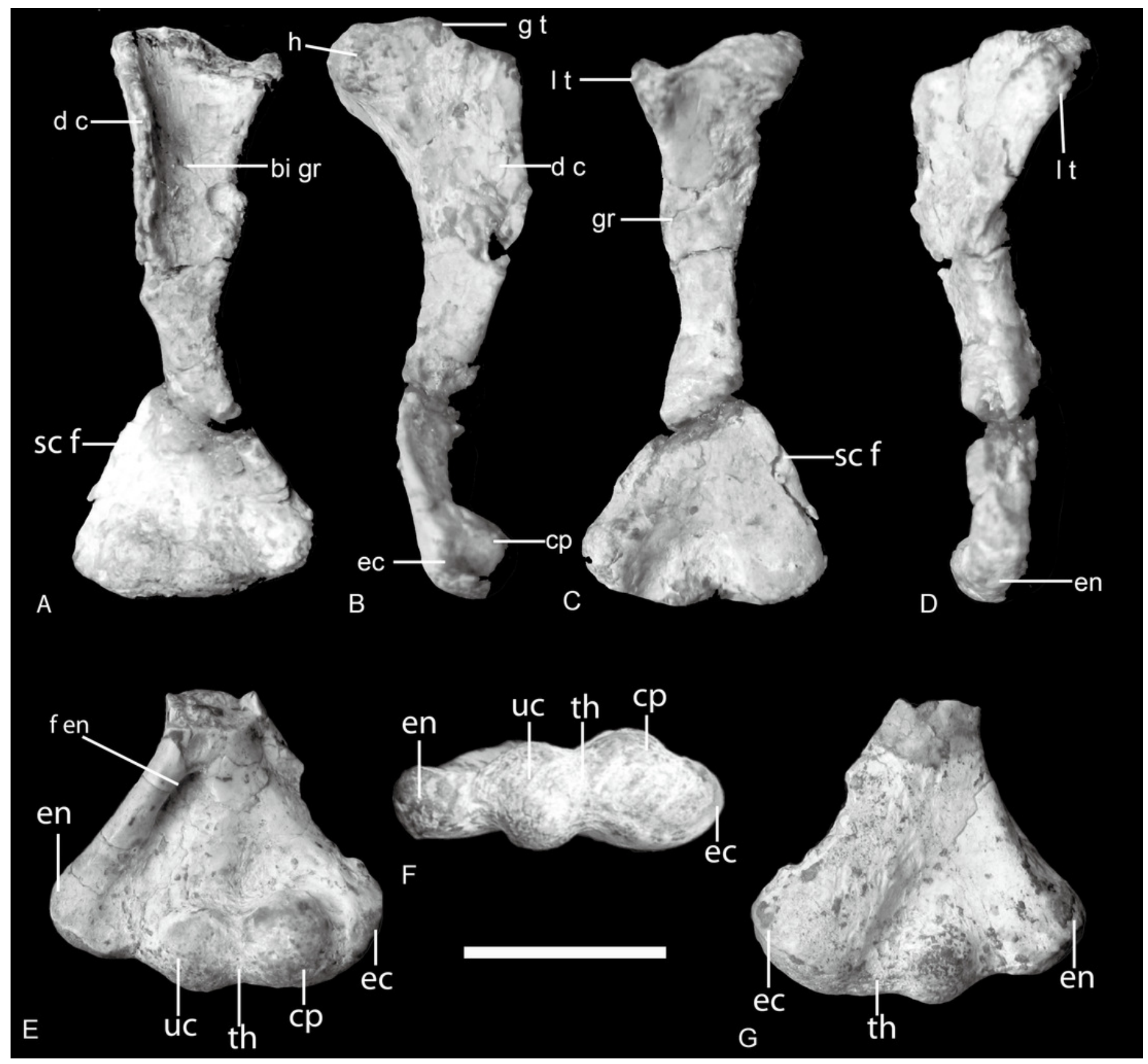




\section{Figure 6}

Boreogomphodon, forelimbs.

Left forelimb (NCSM 21370), (A) manus in plantar view, ulna and radius in posterior view; (B) carpus and metacarpus in plantar view; (C) ulna and radius in anterior view; (D) carpus in dorsal view. Right forelimb (NCSM 20698), (E) manus in plantar view, ulna and radius in posterior view; (F) a few digitals in dorsal view, it continues with digits in (E). Abbreviations:

c, centrale; dc, distal carpal; i, intermedium; mc, metacarpal; paf, proximal articular facet; pc, proximal centrale; $R$, radius; $U$, ulna; r, radiale; $u$, ulnare. Digits in Roman numbers. Scale bars equal $5 \mathrm{~mm}$.

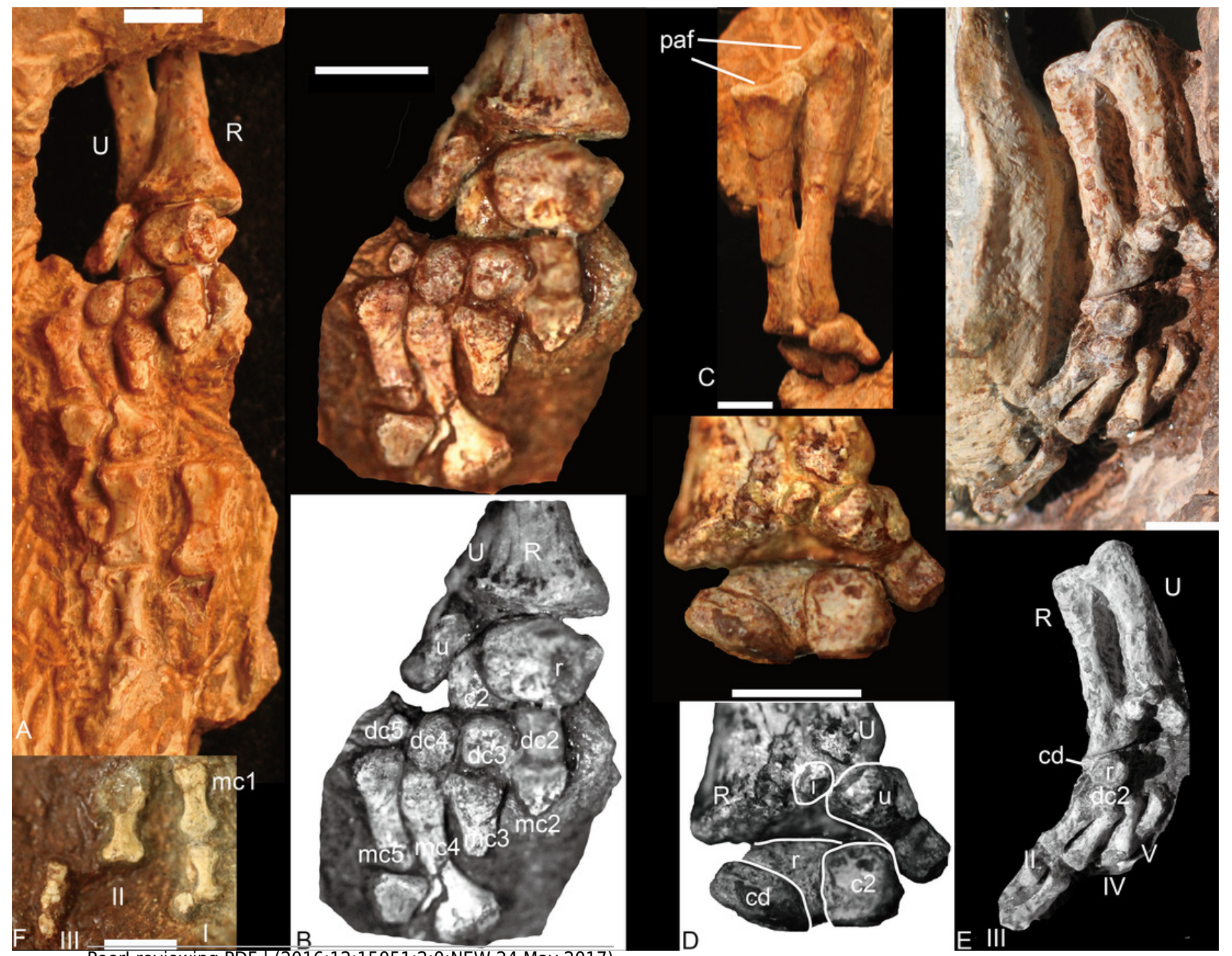




\section{Figure 7}

Boreogomphodon (NCSM 20698), ischium and hindlimb.

(A) hindlimb; (B) left ischium in lateral view; (C) left femur in ventral view, left tibia and left fibula in posterior views; (D) right pes in plantar view. Abbreviation: as, astragalus; ca, calcaneum; cu, cuboid; ecc, ectocuneiform; enc, entocuneiform; FE, femur; Fl, fibula; if, intertrochanter fossa; mec, mesocuneiform; mit, minor trochanter; mjt, major trochanter; mt1 mt4, metatarsal 1 4; n, navicular; p2, second phalange; st, sustentaculum tali; tc, tuber calcis; TI, tibia. Digits in Roman numbers. Scale bars equal $1 \mathrm{~cm}$. 


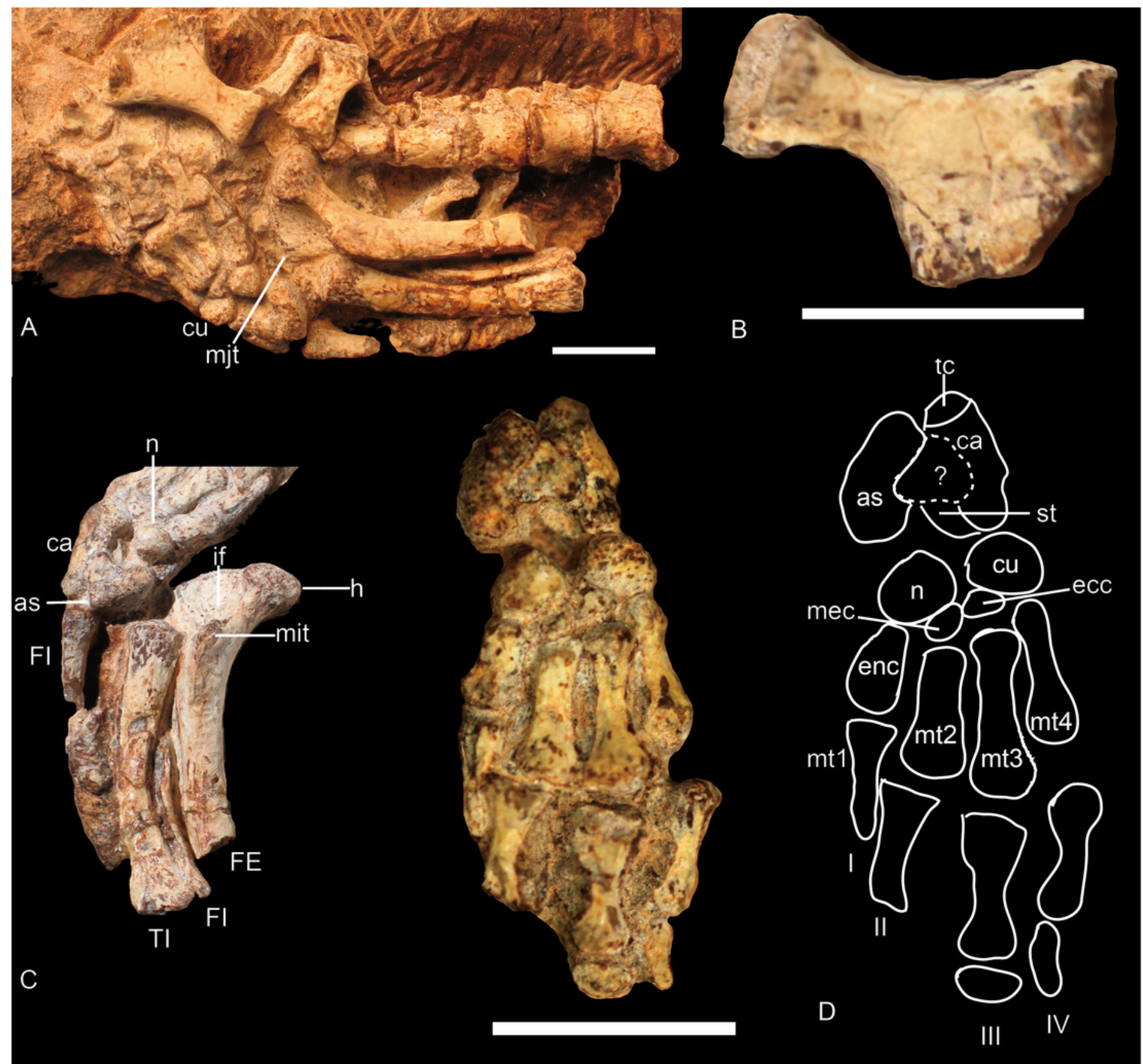




\section{Figure 8}

Different types of ribs in Traversodontidae.

(A) type I, Exaeretodon argentinus (PVL2554); (B) type II, Protuberm cabralensis (UFRGS

PV1010T); (C) type III, Pascualgnathus polanskii (MLP 65-VI-18-2); (D) type IV, Masetognathus pascuali (PVL 5443). (E) Scalenodon angustifrons (NHMUK R9391). Scale bars equal $1 \mathrm{~cm}$.

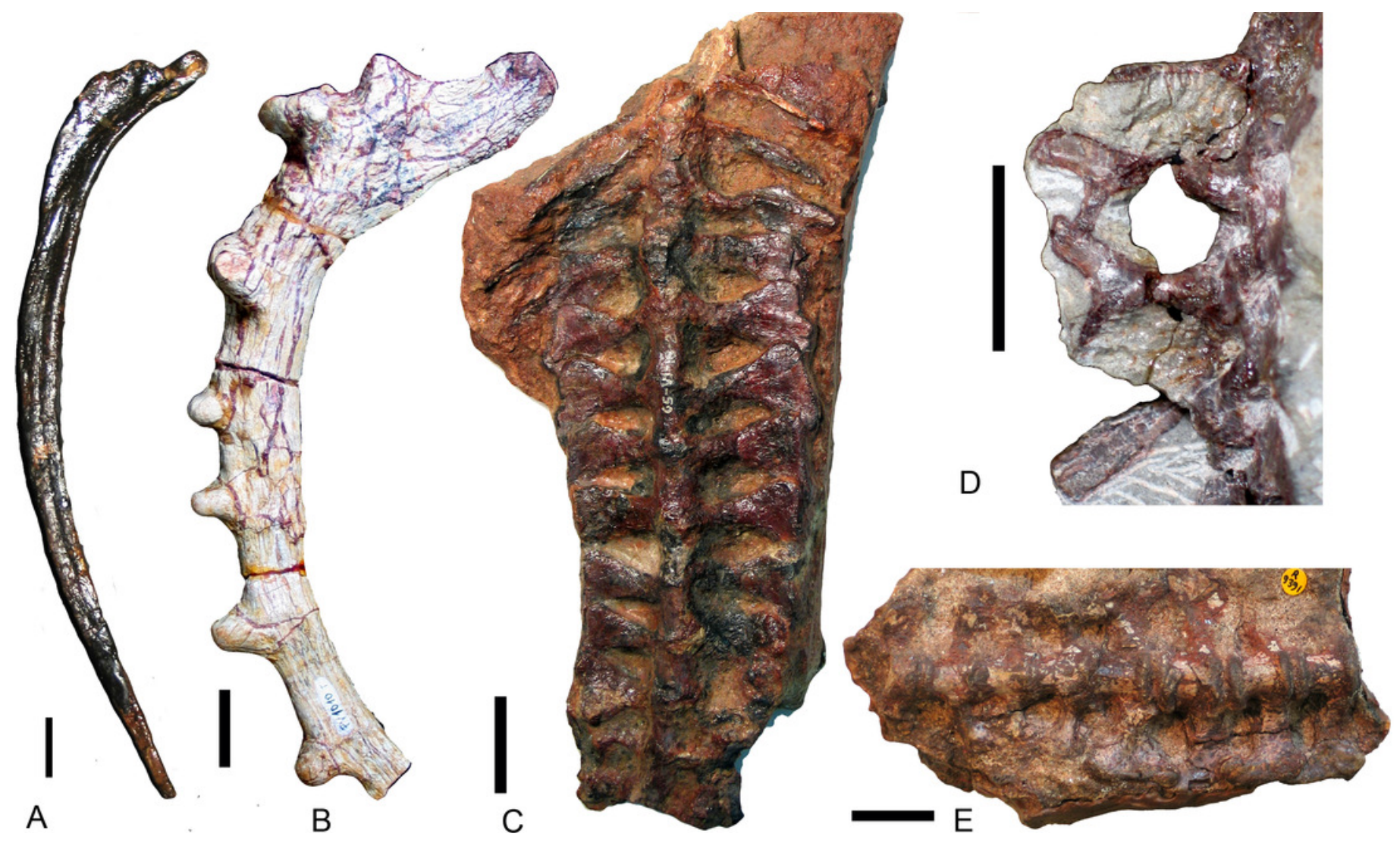


Figure 9

Interclavicles and clavicles.

Exaeretodon argentinus (PVL 2467): (A) right clavicle in ventral view; (B) interclavicle and left clavicle in dorsal view; Massetognathus pascuali (PVL 4613): interclavicle and clavicles in (C) dorsal and (D) ventral views. Scale bars equal $1 \mathrm{~cm}$.

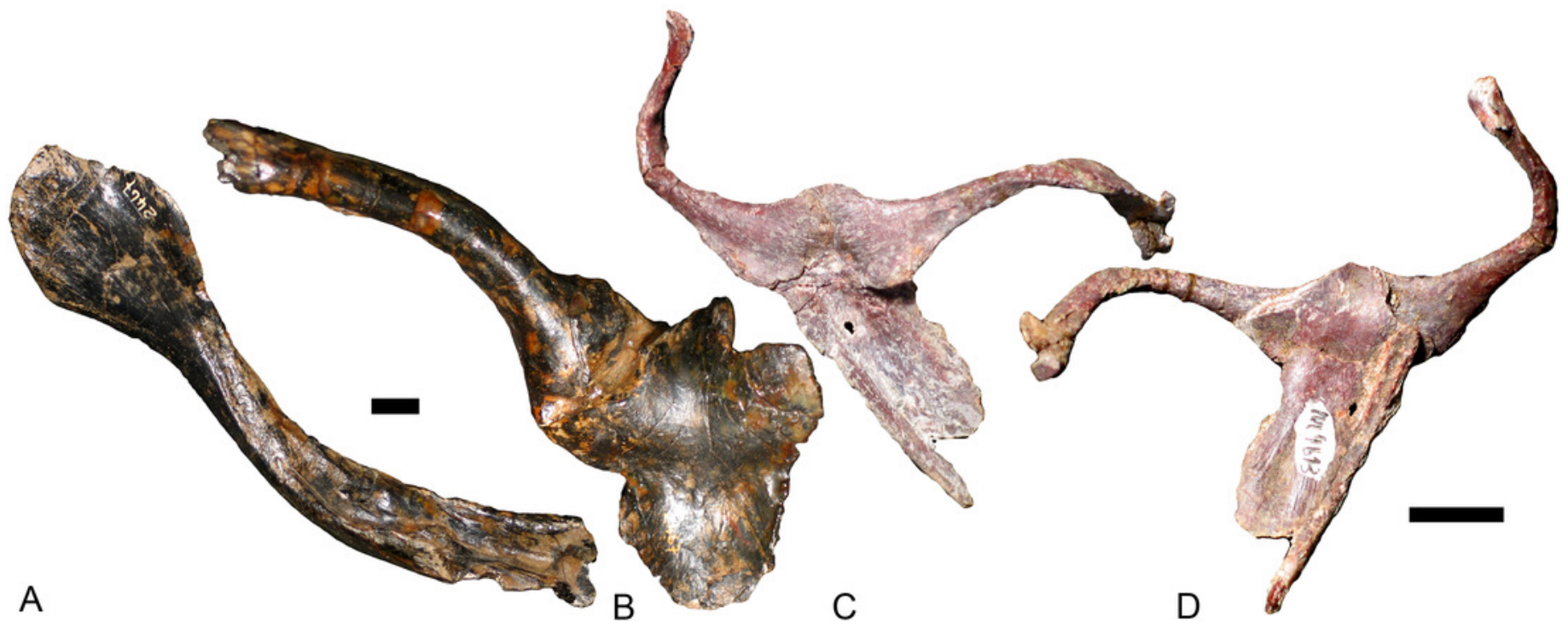




\section{Figure 10}

Scapulocoracoids of various cynodonts.

Cynognathus ( NHMUK 2571) in (A) lateral and (B) medial views; Diademodon (UMZ T 502) in (C) lateral and (D) medial views; Pascualgnathus (MLP 65-VI--18-1) in (E) lateral view; Boreogomphodon (NCSM 20698) in (F) lateral view; Andescynodon mendozensis (PVL 4428) in (G) lateral view; Exaeretodon argentinus (PVL 2554) in (H) lateral view; Luangwa (OUMNH TSK 121) in (I) lateral and (J) medial views; Massetognathus pascuali (PVL 4613) in (K) lateral and (L) medial views; Menadon besairiei (FMNH PR 2444) in (M) lateral and (N) medial views; Traversodon (GPIT RE 1069) in (O) lateral and (P) medial views. Scale bars equal $1 \mathrm{~cm}$.
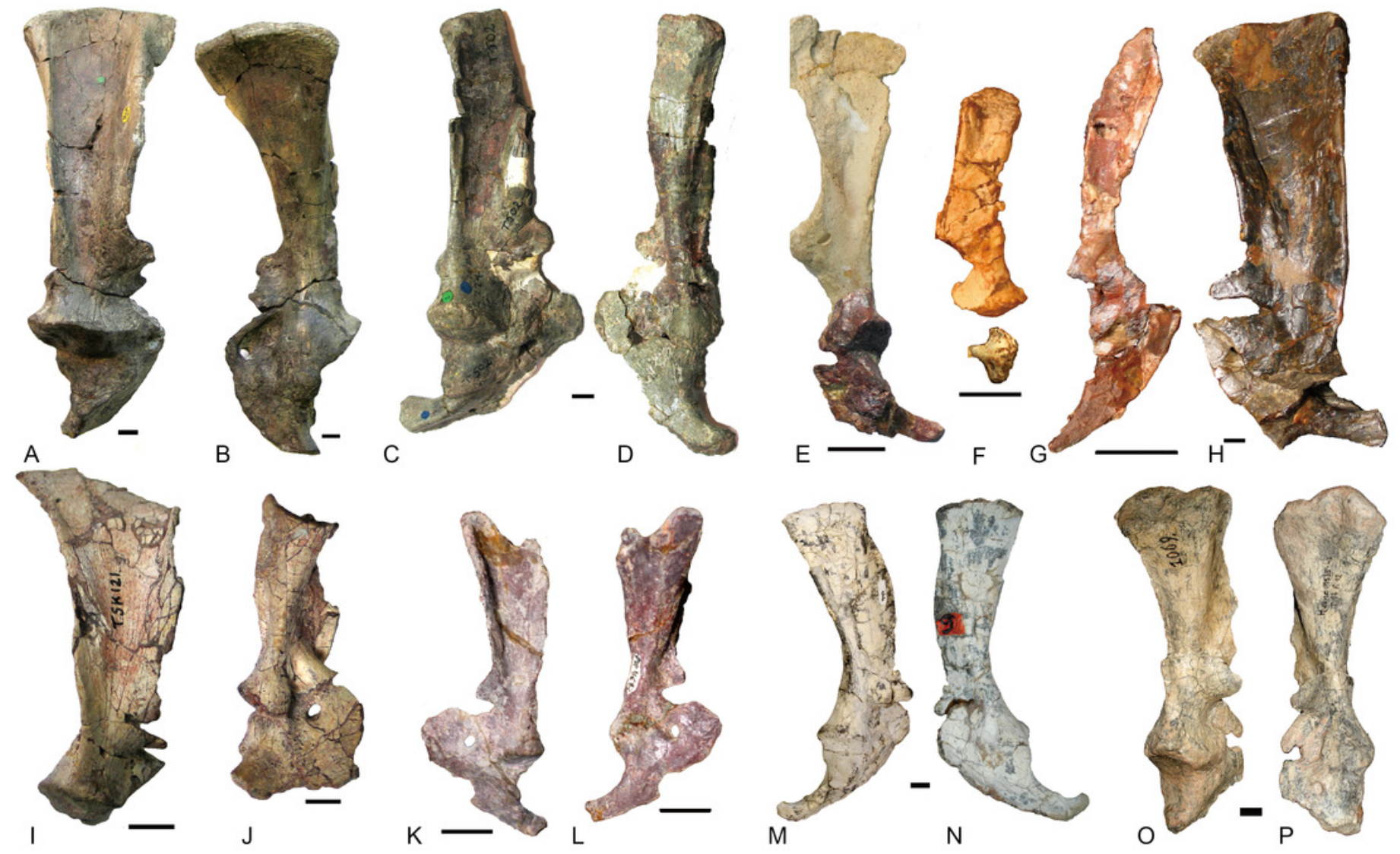
Figure 11

Traversodontid left humeri in ventral view.

(A) Andescynodon mendozensis (PVL 3894); (B) Pascualgnathus polanskii (MLP65-VI-18-1);

(C) Luangwa drysdalli (OUMNH TSK121); (D) Boreogomphodon (NCSM 20698); (E)

Massetognathus pascuali (PVL 4241); (F) Exaeretodon argentinus (PVL 2467). B, D, E are reflected as left side. Scale bars equal $1 \mathrm{~cm}$. 

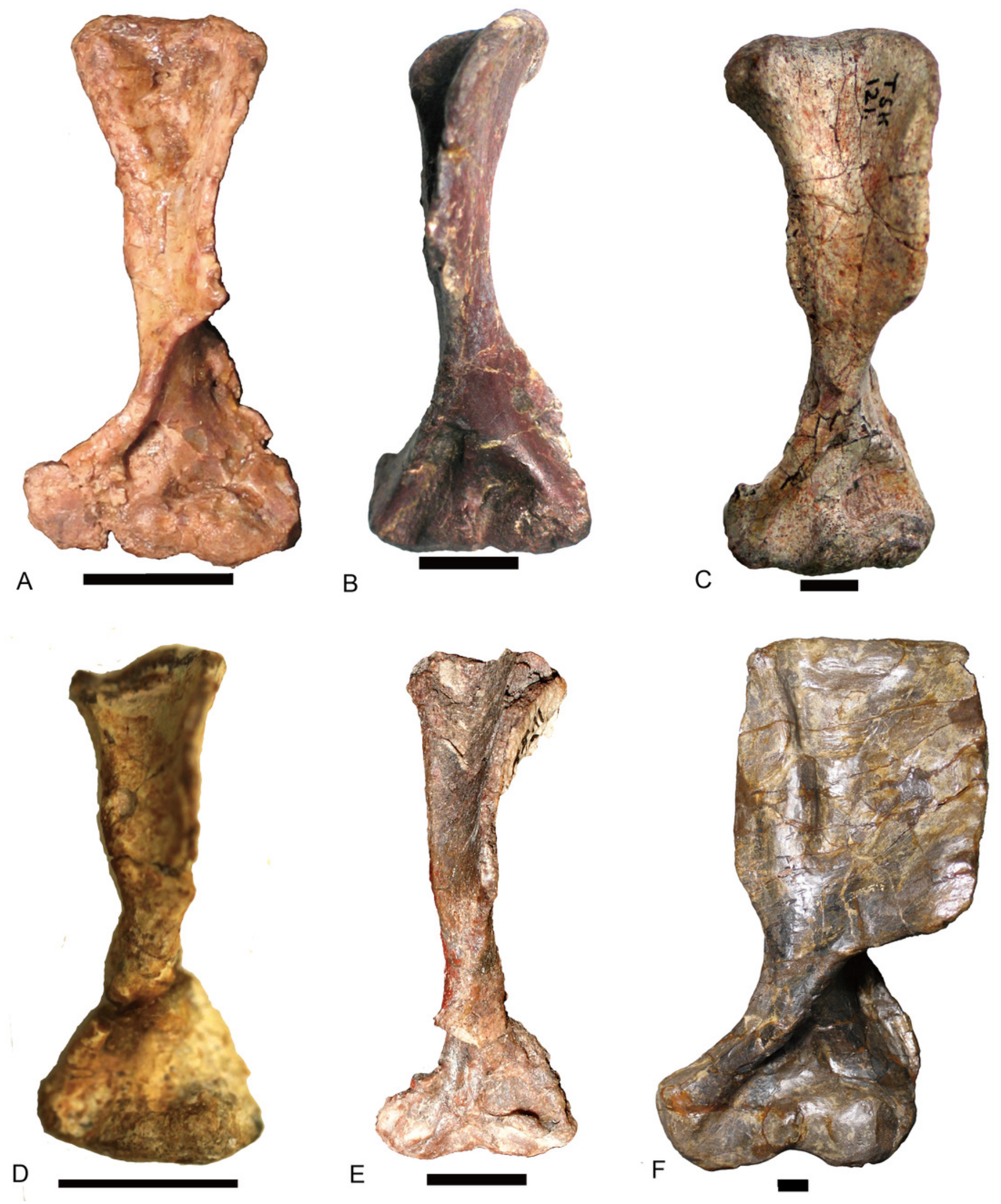
Figure 12

Regression of various width to humeral length (L).

(A) the proximal width (PW), (B) the distal width (DW), (C) the sum of humeral shaft minimum width in dorsoventral and anteroposterior directions $(\mathrm{S} 1+\mathrm{S} 2)$.
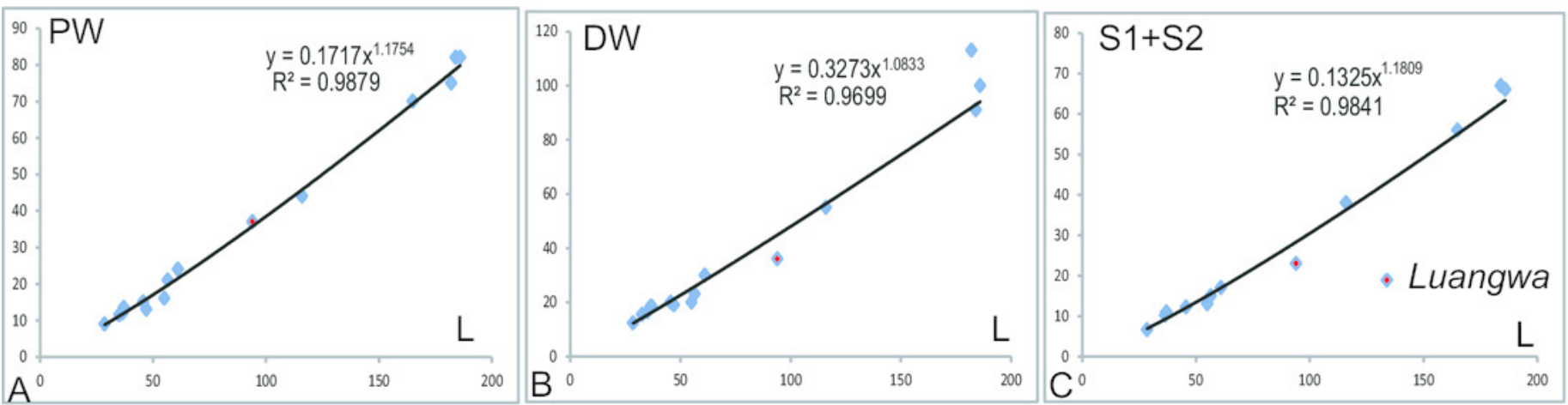
Figure 13(on next page)

Right ulnae of traversodontids in lateral view.

(A) Boreogomphodon (NCSM 20698); (B) Andescynodon (PVL 3890); (C) Pascualgnathus polanskii (MLP 65-VI-18-1); (D) Massetognathus pascuali (PVL 5444); (E) Exaeretodon argentinus (PVL 2467). A, E are reflected as right side. All scale bars equal to $1 \mathrm{~cm}$. 


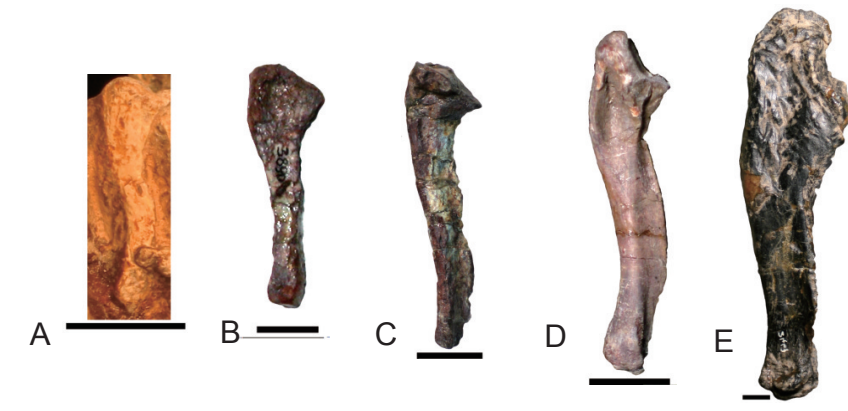




\section{Figure 14}

Pelvises in lateral view.

(A) Scalenodon angustifrons (NHMUK R 9391=TR 8); (B) Pascualgnathus polanskii (MLP 65-VI-

18-1); (C) Andescynodon mendozensis (PVL 3894); (D) Luangwa drysdalli (OUMNH TSK121);

(E) Menadon besairiei (FMNH PR 2444); (F) Massetognathus pascuali (PVL 4442); (G, H)

Exaeretodon argentinus (PVL2554). A, $\mathrm{H}$ are reflected from right side. (I) a trirachodontid (NMQR 3521) right ilium. All scale bars equal to $1 \mathrm{~cm}$.

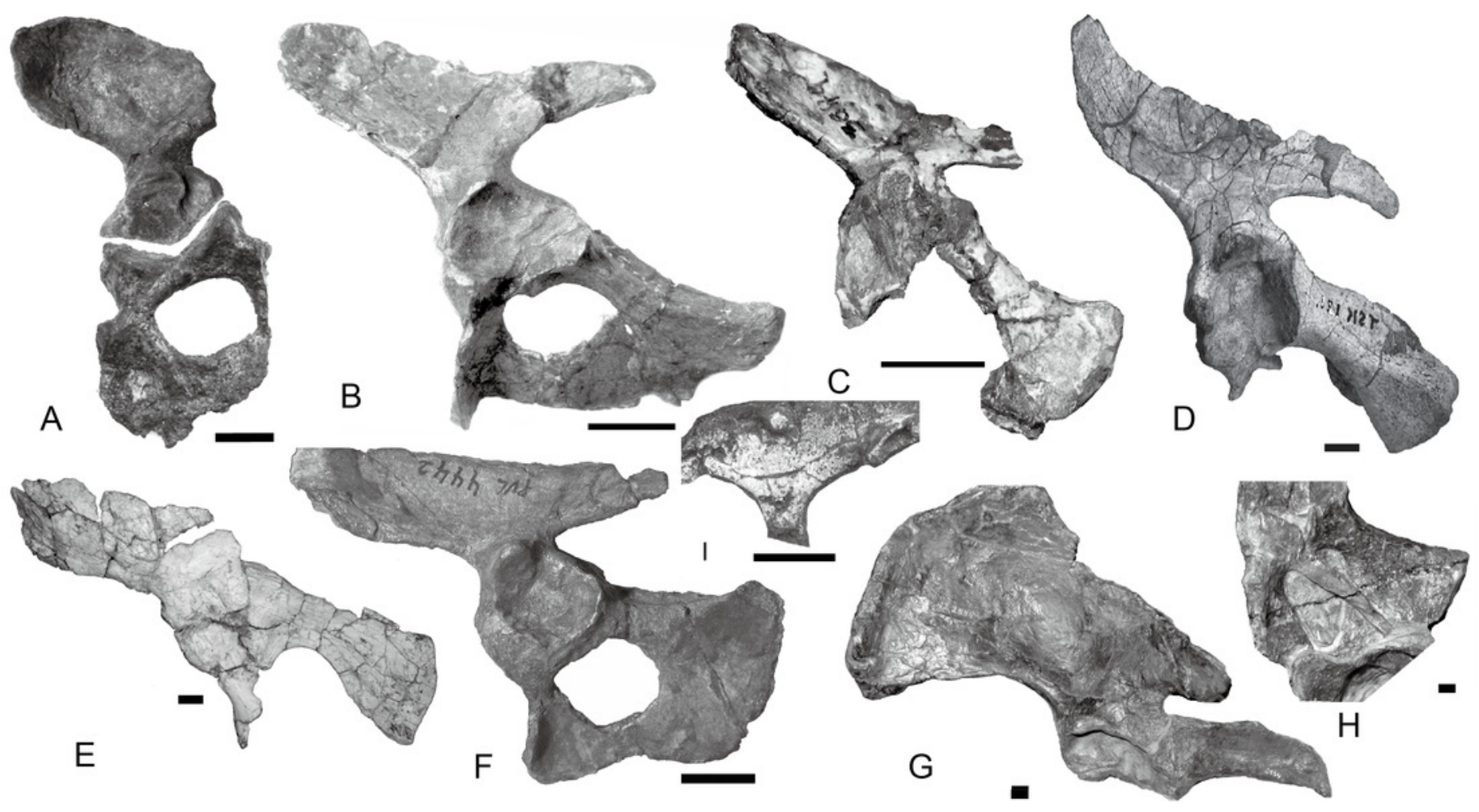




\section{Figure 15}

Femora of traversodontids.

Pascualgnathus polanskii (MLP 65-VI-18-1), right side in (A) anterior and (B) posterior views; Scalenodon angustifrons (NHMUK R9391=TR 8), left side in (C) anterior view; Luangwa drysdalli (OUMNH TSK121), left side in (D) anterior view; Andescynodon mendozensis (PVL 3894), left side in (E) anterior and (F) posterior views; Traversodon stahleckeri (GPIT RE 1069), right side in (G) anterior and (H) posterior views; Massetognathus pascuali (PVL no number), right side in (I) anterior and (J) posterior views; Exaeretodon argentinus (PVL 2554), left side in (K) anterior and (L) posterior views. All scale bars equal to $1 \mathrm{~cm}$. 

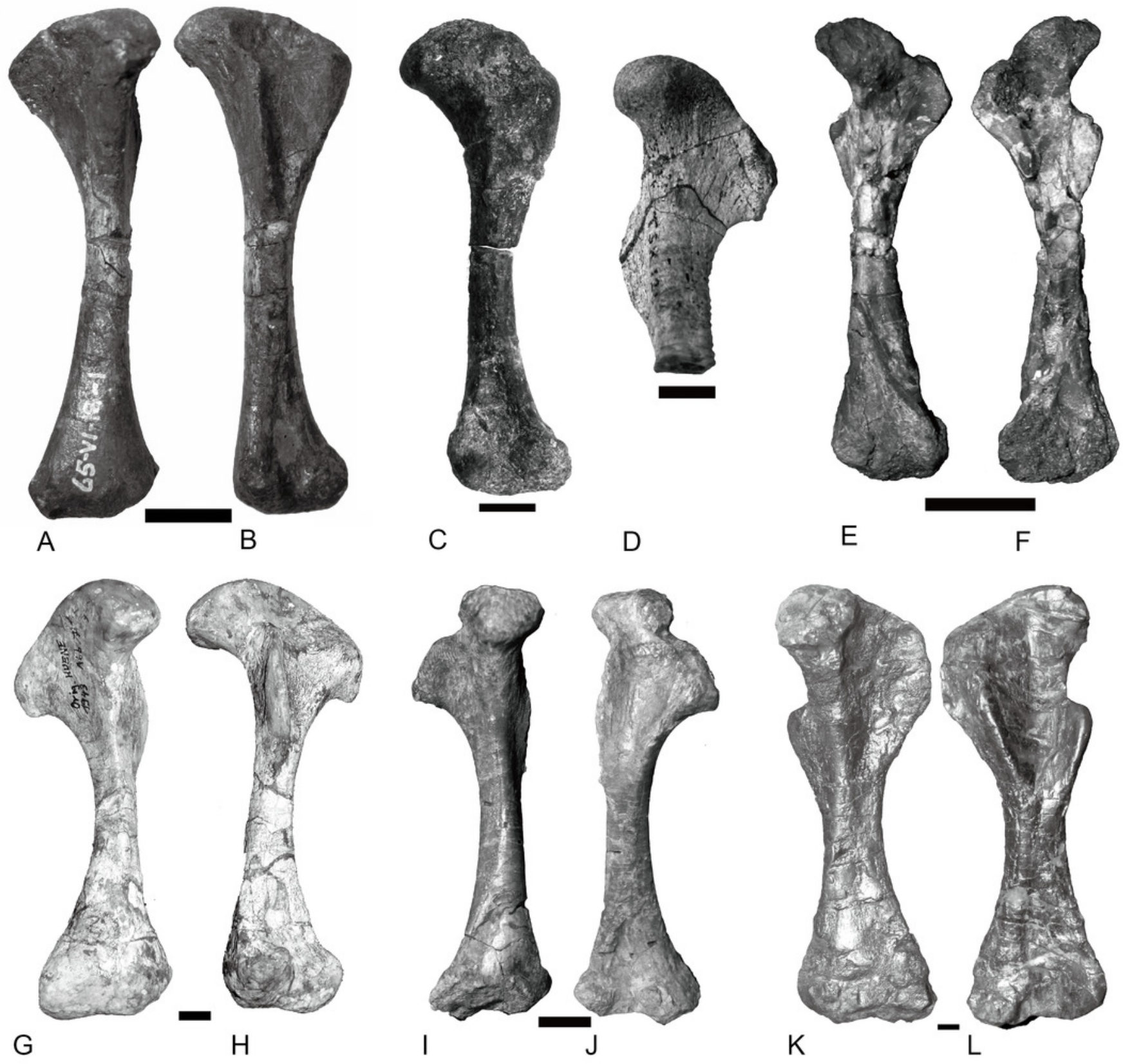
Table $\mathbf{1}$ (on next page)

Measurements of humeri of traversodontids and their ratios 
1 Table 1 Measurements of humeri of traversodontids (in mm) and their ratios

\begin{tabular}{lllll}
\hline Taxa & Specimen & Length & PW DW S1 S2 PW/L DW/L
\end{tabular}

Boreogomphodon NCSM 20698

$28.5 \quad 9 \quad 12.43 .53 .1 \quad 0.32 \quad 0.44$

NCSM 20711

$32.6 \quad 15.5$

0.48

NCSM 21370

3511.516 .5

$0.33 \quad 0.47$

\begin{tabular}{|c|c|c|c|c|c|c|c|c|}
\hline \multirow[t]{3}{*}{ Andescynodon } & \multirow{2}{*}{$\begin{array}{l}\text { PVL } 3894 \\
\text { PVL } 3890\end{array}$} & \multirow{2}{*}{$\begin{array}{r}36.5 \\
37\end{array}$} & \multicolumn{4}{|c|}{1218.55 .54 .7} & \multirow{2}{*}{$\begin{array}{l}0.33 \\
0.36\end{array}$} & \multirow{2}{*}{$\begin{array}{r}0.51 \\
0.5\end{array}$} \\
\hline & & & 3.5 & 18.5 & 6 & 5 & & \\
\hline & PVL 4426 & 45.6 & 15 & 20 & 6.75 & 5.5 & 0.33 & 0.44 \\
\hline \multirow[t]{3}{*}{ Massetognathus } & PVL 4613 & 47 & 13 & 19 & & 5 & 0.28 & 0.4 \\
\hline & PVL 5444 & 55 & 16 & 20 & 6.56 & 6.5 & 0.29 & 0.36 \\
\hline & UNIPAMPA 0625 & 61 & 24 & 30 & 8 & 9 & 0.39 & 0.49 \\
\hline Pascualgnathus & $65-v i-18-1$ & 56.5 & 21 & 23 & 8.56 & 6.5 & 0.37 & 0.41 \\
\hline Luangwa & OUMNH TSK-121 & 94 & 37 & 36 & 12 & 11 & 0.39 & 0.38 \\
\hline \multirow[t]{5}{*}{ Exaeretodon } & UFRGS no number & 116 & 44 & 55 & 22 & 16 & 0.38 & 0.47 \\
\hline & 61-VIII-2-6a & 165 & 70 & & 29 & 27 & 0.42 & \\
\hline & 61-VIII-2-16 & 182 & 75 & 113 & & 35 & 0.41 & 0.62 \\
\hline & PVL 2467 & 184 & 82 & 91 & 35 & 32 & 0.45 & 0.49 \\
\hline & PVL 2554 & 186 & 82 & 100 & 37 & 29 & 0.44 & 0.54 \\
\hline
\end{tabular}

2 Notes: PW: proximal width; DW: distal width; S1, shaft minimum width in dorsoventral

3 direction; S2: shaft minimum width in anteroposterior direction. 
Table 2 (on next page)

Measurements of humeri and ulnae of traversodontids and their ratios 
1 Table 2 Measurements of humeri and ulnae of traversodontids (in mm) and their ratios

\begin{tabular}{lllll}
\hline Taxon & specimen & Humerus & Ulna & Ratio \\
\hline Exaeretodon & PVL 2467 & 184 & 146 & 0.79 \\
Exaeretodon & PVL 2554 & 186 & 144 & 0.77 \\
Massetognathus & PVL 5444 & 55 & 44 & 0.80 \\
Pascualgnathus & MLP 65-VI-18-1 & 56.5 & 43 & 0.76 \\
Boreogomphodon & NCSM 20698 & 28 & 19 & 0.68 \\
Boreogomphodon & NCSM 21370 & 35 & 24 & 0.69 \\
\hline
\end{tabular}

2 


\section{Table 3 (on next page)}

Measurements of hindlimbs 
1 Table 3 Measurements of hindlimbs of traversodontids (in mm)

\begin{tabular}{|c|c|c|c|c|c|c|c|c|}
\hline & & FL & FP & FD & $\mathrm{TL}$ & $\mathrm{TP}$ & TD & FI \\
\hline Boreogomphodon & NCSM 20698 & $>20$ & 10 & & 22 & 5 & 4 & \\
\hline Pascualgnathus & MLP 65-VI-18-1 & 59 & 21 & 15 & 48 & 9.5 & 6.5 & 46 \\
\hline Scalenodon & NHMUK R9391 & 85 & 29 & 22 & & & & \\
\hline Luangwa & OUMNH TSK121 & 99 & 33 & 20 & & & & \\
\hline \multirow[t]{2}{*}{ Andescynodon } & PVL 3894 & 42 & & 11 & & & & \\
\hline & PVL 3890 & 48 & $\sim 20$ & 15 & & & & \\
\hline Traversodon & GPIT RE 1069 & 122 & 55 & 40 & & & & \\
\hline Massetognathus & PVL 5444 & 56 & & 15 & & & & \\
\hline \multirow[t]{2}{*}{ Exaeretodon } & PVL 2554 & 200 & 68 & 67 & 146 & 50 & 32 & 140 \\
\hline & PVL 2162 & 172 & 61 & 52 & & & & \\
\hline
\end{tabular}

2 Notes: FL, femur length; FP, femur proximal width; FD, femur distal width; TL, tibia length; TP, 3 tibia proximal width; TD, femur distal width; FI, fibula length. 